Research Article

Animal Genetics

\title{
Molecular characterization and gene expression analysis of the pro-inflammatory cytokines IL-1 $\beta$ and IL-8 in the South American fish Piaractus mesopotamicus challenged with Aeromonas dhakensis
}

\author{
Mateus Maldonado Carriero ${ }^{1}$ iD, Flavio Henrique-Silva ${ }^{2}$, Caroline Munhoz Meira ${ }^{1}$, Igor Mateus Queiroz \\ Gato $^{1}$, Alexandre Rodrigues Caetano ${ }^{3}$ iD, Francisco Pereira Lobo ${ }^{4}$ iD, Anderson Luis Alves 5 , Eduardo Sousa \\ Varela $^{5}$ and Antonio Augusto Mendes Maia ${ }^{1}$ \\ ${ }^{1}$ Universidade de São Paulo, Faculdade de Zootecnia e Engenharia de Alimentos, Departamento de \\ Medicina Veterinária, Pirassununga, SP, Brazil. \\ ${ }^{2}$ Universidade Federal de São Carlos, Departamento de Genética e Evolução, São Carlos, SP, Brazil. \\ ${ }^{3}$ Embrapa Recursos Genéticos e Biotecnologia, Empresa Brasileira de Pesquisa Agropecuária, Brasília, DF, \\ Brazil. \\ ${ }^{4}$ Embrapa Informática na Agricultura, Empresa Brasileira de Pesquisa Agropecuária, Campinas, SP, Brazil. \\ ${ }^{5}$ Embrapa Pesca e Aquicultura, Empresa Brasileira de Pesquisa Agropecuária, Palmas, TO, Brazil.
}

\begin{abstract}
In the present study, the complete characterization of cDNA and genomic sequences of IL-1 $\beta$ and IL-8, as well as the expression profile of these genes in the South American fish pacu (Piaractus mesopotamicus) is provided. The full-length pmIL- $1 \beta$ cDNA was composed of 1208 nucleotides that would produce a precursor peptide with 273 amino acid residues. A putative caspase- 1 cleavage site, similar to what is found in mammalian IL-1 $\beta$, was identified producing a mature peptide with a theoretical molecular weight of $17.21 \mathrm{kDa}$. The pmIL-8 cDNA sequence consisted of 1019 nucleotides which encoded a 95-amino acid protein with a theoretical molecular weight of $10.43 \mathrm{kDa}$ that showed all typical CXC chemokine features, including a 20-residue signal peptide and four conserved cysteine residues. Constitutive mRNA expression was detected for both genes in the liver, head kidney, gill, intestine, skin and spleen. After a bacterial challenge, up-regulation was detected for both pmIL-1 $\beta$ and pmIL-8 in the spleen and head kidney at $12 \mathrm{~h}$ post-infection. At $24 \mathrm{~h}$ post-infection there was a decrease in the expression of both genes, with pmlL-8 showing a significant down-regulation in the liver and head kidney when compared to the control groups.
\end{abstract}

Keywords: Bacterial infection, fish immunology, gene expression, interleukin, South American fish.

Received: January 14, 2020; Accepted: August 6, 2020.

\section{Introduction}

Aquaculture is a constantly developing economic activity in Brazil and the characiform Piaractus mesopotamicus (Holmberg 1887), commonly known as "pacu", is the second most produced native species with increasing importance in global aquaculture due to its desired characteristics such as easy reproduction, ecological value and marketability (Witmer and Fuller, 2011; MPA, 2013; Lin et al., 2015).

However, the increase of its production in fish farms, frequently in intensive systems, facilitates the occurrence of disease outbreaks, leading to substantial economic losses. Among the infectious diseases commonly observed in farmed pacus, some of the most important are the ones caused by bacteria of the Aeromonas genus, which have been asso-

Send correspondence to Mateus Maldonado Carriero. Universidade de São Paulo, Faculdade de Zootecnia e Engenharia de Alimentos, Departamento de Medicina Veterinária, 13635-900, Pirassununga, SP, Brazil. E-mail: mateus.maldonado@usp.br. ciated with septicemia-induced mortality outbreaks in this species in Brazil (Carriero et al., 2016; Claudiano et al., 2019; Marinho-Neto et al., 2019). Furthermore, the lack of knowledge regarding immune responses in $P$. mesopotamicus prevents the development of appropriate treatments and prophylactic strategies to decrease the frequency in which these outbreaks occur (Farias et al., 2018).

Pro-inflammatory cytokines are a class of small proteins involved in the communication between cells of the immune system that are generally characterized as key initiators of inflammatory processes after the detection and recognition of infections (Secombes et al., 2011; Pleic et al., 2014). Two of the most studied pro-inflammatory cytokines are the interleukin-1 $\beta$ (IL-1 $\beta$ ) and interleukin-8 (IL-8) due to their critical importance in the initiation and maintenance of inflammations (Dinarello, 1997; Kendrick et al., 2014).

Several studies have shown the importance of IL- $1 \beta$ and IL- 8 in the regulation of inflammatory responses during 
bacterial and parasitic infections, and the analysis of their expression is recognized as good indicators of the occurrence of inflammatory processes (Morrison, 2012; Herath et al., 2016; Wang et al., 2017; Wang et al., 2019). Recently, these cytokines have also been recognized as potential molecular adjuvants in fish vaccination, with promising results already obtained against viral and bacterial pathogens (Peddie et al., 2003; Jimenez et al., 2006; Sanchez, 2007; Wang et al., 2016; Wang et al., 2019), further increasing the importance of studies providing their structural and functional characterization.

In mammals, IL- $1 \beta$ is produced as an inactive precursor molecule (proIL-1 $\beta$ ) that needs to be cleaved by the proteolytic enzyme caspase-1, also known as IL- $1 \beta$ converting enzyme (ICE) in a conserved aspartic acid (Asp) residue, usually between the positions 113 and 117 , to produce the bioactive form, which is then secreted by the cells (Secombes et al., 1999; Zou et al., 1999). In fish species, the exact mechanism involved in the cleavage of proIL-1 $\beta$ into the mature biologically active form is still not fully elucidated. Although the caspase-1 cleavage site reported for humans is usually absent, for some species such as sea bass (Dicentrarchus labrax), a caspase-1-dependant cleavage mechanism has been described for the production of mature IL-1 $\beta$ peptide, however, in different aspartic acid residues (Reis et al., 2012).

IL-8, also known as CXCL-8, is a small (8-12 kDa) chemokine produced by several immune related cell types such as lymphocytes, macrophages, peripheral blood mononuclear cells and epithelial cells (Goodman et al., 1991; Nakamura et al., 1991; Mukaida et al., 1998). It is involved in the chemotactic attraction of immune cells during inflammatory reactions, mainly recruiting neutrophils and other important leukocytes to the infection or injury location ( $\mathrm{Li}$ and Yao, 2013). In mammalian IL-8, a three-amino acid residue motif (Glu-Leu-Arg) is commonly found preceding the first cysteine $\left(\mathrm{ELR}^{+} \mathrm{CXC}\right)$. The presence of this motif confers to proteins the ability to exert a chemoattractant effect on leukocytes, as well as to promote angiogenesis (Allen et al., 2007; Harun et al., 2008; Herath et al., 2016). In teleost fish, however, this motif has not been identified in any species, with the exception being haddock (Melanogrammus aeglefinus), which has led to the speculation of whether fish IL-8 might have fewer functions than their mammalian counterparts, a hypothesis that is still not confirmed (Seppola et al., 2008).

Most of the studies investigating the structural and functional characteristics of fish IL- $1 \beta$ and IL- 8 have been performed mainly with representatives of the Salmoniformes, Cypriniformes, Siluriformes and Perciformes orders, with no studies providing a detailed analysis of the structure and expression analysis under pathogenic infections of IL$1 \beta$ and IL- 8 of fish from the Characiformes order being found in the literature.

Therefore, the present study aims to provide the characterization of the complete cDNA sequences, as well as the genomic regions, of the cytokines IL- $1 \beta$ and IL- 8 from the
South American fish pacu. Complete sequence analysis including a phylogenetic comparison of the obtained sequences with the sequences from other vertebrates, domain architecture and secondary and tertiary structures of the deduced proteins are provided. Moreover, the tissue distribution and expression profile of these cytokines in the liver, spleen and head kidney of bacteria-infected fish were investigated.

\section{Materials and Methods}

\section{Ethics statement}

All animal handling was performed following the Brazilian animal welfare guidelines (Federal Law $\mathrm{n}^{\circ} 11.794$ dated October $8^{\text {th }}, 2008$ ) and the present study was approved by the ethics committee for animal welfare of the Faculty of Animal Science and Food Engineering of the University de São Paulo (FZEA/USP) under the protocol number 14.1.391.74.9.

\section{Experimental fish}

Pacus (weighing $33.8 \pm 4.8 \mathrm{~g}$ ) used in the present experiment were purchased from a local fish farm and maintained in $40 \mathrm{~L}$ glass tanks with filtered dechlorinated tap water under constant aeration with controlled temperature at $27 \pm 2{ }^{\circ} \mathrm{C}$ and with a controlled photoperiod of $12 \mathrm{~h}: 12 \mathrm{~h}$ of light/darkness. Fish were fed twice a day with a commercial dry pelleted feed until satiation. A third of the water of each tank was replaced every two days to prevent accumulation of organic matter. Fish were maintained under these conditions for three weeks prior the experiments for acclimation.

\section{Pacu IL-1 $\beta$ and IL-8 cDNA and genomic DNA cloning}

For the initial characterization of the genes IL- $1 \beta$ and IL-8, total RNA was isolated from approximately $30 \mathrm{mg}$ of head kidney, spleen and liver using TRIzol ${ }^{\circledR}$ Reagent (Thermo Fisher Scientific) following the manufacturer's protocol, quantified in a NanoDrop 2000 (Thermo Scientific) spectrophotometer at $260 \mathrm{~nm}$ and analyzed by agarose gel electrophoresis to assess the integrity of the samples. Prior to reverse transcription reactions, in order to eliminate possible genomic DNA contamination, samples were treated with 1 unit of RQ1 RNase-free DNase (Promega) per $\mu \mathrm{g}$ of RNA. DNase treated RNAs were then subjected to cDNA synthesis using the High Capacity Reverse Transcription Kit (Applied Biosystems) following manufacturer's instructions.

For the initial amplification of $P$. mesopotamicus IL$1 \beta$ and IL- 8 (pmIL- $1 \beta$ and pmIL- 8 ) fragments, primers were designed based on conserved regions of the predicted sequences of the red-bellied piranha (Pygocentrus nattereri, GenBank accession numbers XM_017693723 for IL-1 $\beta$ and XM_017685589 for IL-8) and tambaqui (Colossoma macropomum) (unpublished data), other South American characiforms from the Serrasalmidae family (Table 1). Amplified fragments were purified, ligated to the GEM $^{\circledR}$-T Easy Vec- 
tor (Promega) and transformed into DH5 $\alpha$ Escherichia coli competent cells, which were then inoculated on LB-agar plates supplemented with $100 \mu \mathrm{g} / \mathrm{mL}$ ampicillin, $0.5 \mathrm{mM}$ IPTG and $50 \mathrm{mg} / \mathrm{mL} \mathrm{X}$-Gal. Ligated plasmids were recovered using the PureYield ${ }^{\mathrm{TM}}$ Plasmid Miniprep System (Promega) and sequenced using the T7 - SP6 primers as well as specific internal primers for each gene (Table 1).

The complete cDNA sequences of pmIL-1 $\beta$ and pmIL-8 were amplified using the 3' and 5' RACE System for Rapid Amplification of cDNA Ends Kits (Invitrogen), cloned and sequenced as described above. For characterization of the complete genomic sequences, gDNA was isolated from pacu tail fin clips using the Dneasy ${ }^{\circledR}$ Blood \& Tissue Kit (Qiagen) following the manufacturer's instructions and amplified using primers designed based on the full-length cDNA of pmIL-1 $\beta$ and pmIL-8 (Table 1).

\section{P. mesopotamicus IL-1 $\beta$ and IL-8 sequence analysis}

The obtained full-length cDNA sequences were translated to obtain the putative amino acid sequences of pmIL$1 \beta$ and pmIL-8 using the online Sequence Manipulation Suite (Stothard, 2000) (https://www.bioinformatics.org/sms/index.html). The exon/intron structure of the genomic sequences was determined by comparing the obtained cDNA and genomic sequences using the Splign software (Kapustin et al., 2008).

Theoretical isoelectric points (pI) and molecular weights (Mw) of the deduced amino acid sequences were estimated using the Compute $\mathrm{pI} / \mathrm{Mw}$ tool and characteristic signature domains and structures were predicted using the Prosite server on the ExPASy Bioinformatics Resource Portal (http://web.expasy.org/compute_pi/). Disulfide bonds were predicted using the DiANNA web server for cysteine classification and disulfide connectivity prediction (Ferre and Clote, 2006).

The tertiary structure of pmIL- $1 \beta$ and pmIL- 8 was predicted using the online SWISS model interface (Arnold et al., 2006) with the $2.10 \AA$ resolution human IL-1 $\beta$ crystal structure (SMTL ID 5i1b.1) and the human $2.00 \AA$ resolution IL-8 crystal structure (SMTL ID 3il8.1), respectively. Three-dimensional (3D) images were visualized and edited using UCSF Chimera molecular graphics software version 1.13.1 (Pettersen et al., 2004).

Multiple sequence alignments were produced using Clustal W (Thompson et al., 1994) to analyze the relationship between pmIL-1 $\beta$ and pmIL- 8 amino acid sequences and other vertebrate species. Neighbor Joining phylogenetic analysis was performed based on the Poisson correction model and bootstrapped 1000 times using MEGA 7 software (Kumar et al., 2016).

\section{Bacterial challenge}

For the experimental infections, a pathogenic strain of Aeromonas dhakensis, which was previously isolated from diseased pacu fish during an outbreak in Brazil (Carriero et al., 2016), was cultured for $24 \mathrm{~h}$ at $30{ }^{\circ} \mathrm{C}$ in Tryptic Soy Broth (TSB) (BD Difco ${ }^{\mathrm{TM}}$ ) containing $10 \mathrm{mg} / \mathrm{mL}$ of ampicillin with constant shaking until an optical density of 0.4 at $600 \mathrm{~nm}$ was obtained. This culture was then diluted to the concentration of $4.4 \times 10^{4} \mathrm{CFU}$ in $0.1 \mathrm{~mL}$ of sterile $0.9 \%$ $\mathrm{NaCl}$ saline solution. This inoculum, which represented the lethal dose for $20 \%$ of the infected fish for this bacterial strain as previously described, was administered to each fish by intraperitoneal injection (Carriero et al., 2016, 2018). Fifty pacus were inoculated with $0.1 \mathrm{~mL}$ of the bacterial inoculum and randomly divided into five $40 \mathrm{~L}$ glass tanks to

Table 1 - Primers used for $P$. mesopotamicus IL- $1 \beta$ and IL-8 cloning and expression analysis.

\begin{tabular}{|c|c|c|c|c|}
\hline Primer & Target gene & Sequence (5'-3') & Product size & Use \\
\hline IL-1 $1 \beta F 1$ & IL-1 $\beta$ & ACTGGACTGCTCTGATCCTTTG & 639 bp & Initial amplification \\
\hline IL-1 $1 \beta R 1$ & & CAGCCTGGGTACTTCACTGATT & & \\
\hline IL-1 $1 \beta \mathrm{F} 2$ & & ACCGTGTGTGACAGCTTAAAGA & 94 bp & qPCR and RACE \\
\hline IL-1 $1 \beta R 2$ & & TTTGGCTACTGTTTCCACCCTT & & \\
\hline IL-1 $1 \beta \mathrm{F} 3$ & & GAGCTGAAAGACTACAGCTAAACT & $2021 \mathrm{bp}$ & gDNA amplification \\
\hline IL-1 $1 \beta \mathrm{R} 3$ & & GTCTTGGACGTTACAACACCAG & & \\
\hline IL-8F1 & IL-8 & GTGGGGGTGTGTTTATTTTTGG & $288 \mathrm{bp}$ & Initial amplification \\
\hline IL-8R1 & & ATCTTGTGTCTGACCTTAGGGTG & & \\
\hline IL-8F2 & & AGACGGATCGGCAAACTGATAGA & 90 bp & qPCR and RACE \\
\hline IL-8R2 & & GTTCTTTAGCGTCGCTATGATCT & & \\
\hline IL-8F3 & & AGCTGAAACTCCAGACACAGTC & 2045 bp & gDNA amplification \\
\hline IL-8R3 & & TGTCCAAAGTTACTCATGCCTCT & & \\
\hline BactF & $\beta$-actin & TCACAGAGGCTCCCCTGAAC & $64 \mathrm{bp}$ & qPCR \\
\hline BactR & & CTCAAACATGATCTGGGTCATCT & & \\
\hline $\mathrm{T} 7$ & Vector & TAATACGACTCACTATAGGG & - & Plasmid sequencing \\
\hline SP6 & & TATTTAGGTGACACTATAG & & \\
\hline
\end{tabular}


a final density of ten fish per tank. For the control group, 50 pacus were injected with $0.1 \mathrm{~mL}$ of sterile $0.9 \% \mathrm{NaCl}$ saline solution.

During the experimental period, seven fish from the infected group died after the bacterial inoculation. These fish were immediately removed from the tanks and processed for re-isolation of the bacteria by inoculating macerated fragments of organs on Tryptic Soy Agar (TSA) (BD Difco ${ }^{\mathrm{TM}}$ ) with no antibiotics, followed by PCR amplification with Aeromonas specific primers to confirm the infection (Yanez et al., 2003). Also, several specimens that survived the infection and were used in the gene expression experiment showed clinical signs associated with Aeromonas-induced acute hemorrhagic septicemia, which included hemorrhagic foci in the eyes, gills, fins and anal region, abdominal swelling, erratic swimming and darkening of the skin (Carriero et al., 2016). No fish from the control group showed any clinical signs or clear behavioral alteration.

After the experiments, five fish from the control group were tested using the same isolation protocol, with no bacterial DNA being detected (data not shown).

\section{P. mesopotamicus IL-1 $\beta$ and IL-8 tissue distribution and expression analysis following infection with $A$. dhakensis}

To evaluate transcript levels of the cytokines IL-1 $\beta$ and IL-8 under physiological conditions, mRNA was quantified in the liver, spleen, head kidney, gills, intestine and skin of five healthy uninfected pacus. At the time of sampling, these fish were euthanized by lidocaine overdose, visually analyzed for the presence of any signs of infections, such as excess of mucus and changes in the color of skin and gills and hemorrhagic foci in the internal organs, as well as for the occurrence of any parasitic infection, and fragments of each organ were aseptically collected.

To assess the role of these interleukins during the infection with the bacterium $A$. dhakensis in pacu, five fish from the infected and control groups were euthanized and fragments of liver, spleen and head kidney were aseptically collected at 12, 24 and $48 \mathrm{~h}$ post-infection. All samples were immediately frozen in liquid nitrogen and subjected to RNA extraction and cDNA synthesis as described above.

The determination of pmIL- $1 \beta$ and pmIL- 8 mRNA levels was performed by quantitative real-time PCR (qPCR) using specific primers designed based on the obtained full-length cDNA sequences (Table 1). Prior to expression analyses, each primer pair was tested for amplification efficiency by creating a standard curve with serial dilutions of the cDNA of a representative sample using the formula $\mathrm{E}=$ $\left(10^{-1 / \text { slope }}-1\right) \times 100$. This efficiency analysis was performed three times for each gene and the average efficiencies were $101.7 \%$ for IL- $1 \beta$ and $94.5 \%$ for IL- 8 . The same efficiency analysis was performed for the $\beta$-actin gene, which was used as endogenous reference with previously described primers (de Paula et al., 2014).

Quantitative PCR (qPCR) reactions were performed in duplicates with a final volume of $10 \mu \mathrm{L}$ consisting of $5 \mu \mathrm{L}$ of
GoTaq $^{\circledR}$ qPCR Master Mix, $300 \mathrm{nM}$ of each primer, $10 \mathrm{ng}$ of cDNA and MiliQ ultrapure water using a Quantstudio ${ }^{\text {TM }} 6$ Flex Real-Time PCR System (Applied Biosystems). A notemplate control (NTC) reaction was performed for each gene on each run and, immediately after every amplification, a melt curve analysis was performed to verify the occurrence of unspecific amplification or primer dimers.

The relative expression levels were obtained by subtracting the mean $\mathrm{Ct}$ values of the target genes from the mean $\beta$-actin values $(\Delta \mathrm{Ct})$ which were applied to the $2^{-\Delta \mathrm{Ct}}$ algorithm (Schmittgen and Livak, 2008). For the basal expression analysis, data are presented as relative fold-change to the liver for IL-1 $\beta$ and to the intestine for IL- 8 , which were the organs with the lowest expression levels. For expression analysis of the bacteria-infected fish, data are presented as relative fold-change to the control samples at the same time point.

\section{Statistical analysis}

Relative gene expression data were analyzed for variance (ANOVA) and the means were compared using the Student's $t$-test to assess the differences of gene expression between the infected and control groups at the same time point. The pmIL- $1 \beta$ and pmIL- 8 distribution analysis among different tissues was performed using Tukey's test. The equality of variance was tested by Levene's test and the normality was assessed using the Kolgomorov-Smirnov test. Differences were considered statistically significant when $p \leq$ 0.05 .

\section{Results}

\section{Characterization and sequence analysis of $P$. mesopotamicus IL-1 $\beta$ and IL-8}

The full-length cDNA sequence of pmIL-1 $\beta$ (GenBank accession number MT787039) was composed of 1208 nucleotides, subdivided in a 5' untranslated region (UTR) of 76 $\mathrm{nt}$, an open reading frame (ORF) of $822 \mathrm{nt}$, and a 3' UTR of $310 \mathrm{nt}$ containing a polyadenylation signal (AATAAA) $19 \mathrm{nt}$ upstream the poly A tail and three instability motifs (ATTTA), which are typically observed in mRNAs from inflammatory cytokines, indicating that the expression of these proteins is highly regulated (Scapigliati et al., 2001) (Figure 1A).

The putative sequence of pmIL-1 $\beta$ precursor protein was composed of 273 amino acid residues with a theoretical molecular weight of $30.54 \mathrm{kDa}$ and an isoelectric point of 5.14. A putative caspase- 1 cleavage site was identified between $\mathrm{Asp}^{114}$ and $\mathrm{Arg}^{115}$ producing a mature active peptide composed of 157 amino acid residues with a theoretical molecular weight of $17.21 \mathrm{kDa}$ and an isoelectric point of 8.25.

The multiple sequence analysis showed that this putative caspase- 1 cleavage aspartic acid observed in pmIL- $1 \beta$ is also present in the predicted sequences of the red-bellied piranha and cave fish, the other characiform species included in the analysis (Figure 2A). The only non-chaciform species with this aspartic acid in the same position was the channel 
A

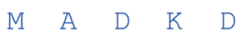

1 tgagaagagctgaaagactacagctaaactgctagaacaatttcacgcaatttctgaaggcttcctaacctcCgaaATGGCAGACAAGGA

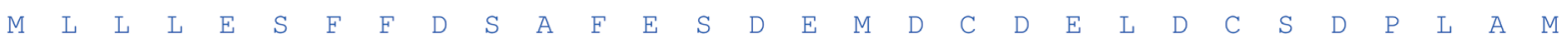

91 TATGCTGCTGTTGGAAAGCTTCTTCGACAGCGCATTTGAGTCTGATGAGATGGATTGTGATGAACTGGACTGCTCTGATCCTTTGGCCAT

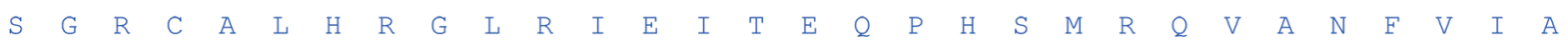

181 GAGTGGCAGGTGTGCTTTACACAGAGGGCTACGGATTGAAATTACTGAGCAGCCTCACAGTATGAGACAAGTGGCAAATTTCGTAATTGC

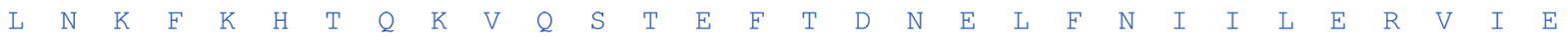

271 TCTAAACAAGTTCAAGCACACTCAGAAAGTCCAGTCCACAGAATTCACCGACAATGAGCTATTCAACATTATCTTGGAGCGTGTAATTGA

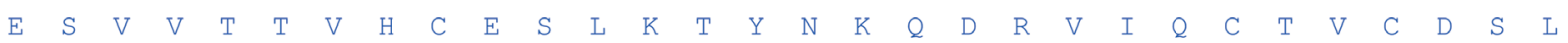

361 AGAGAGTGTGGTGACGACGGTACATTGTGAATCTTTAAAGACTTACAACAAGCAAGATAGAGTCATCCAGTGTACCGTGTGTGACAGCTT

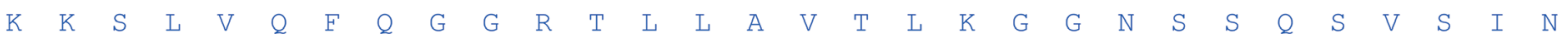

451 AAAGAAGAGCCTGGTGCAGTTTCAAGGTGGCCGCACCCTCTTAGCAGTCACTCTGAAGGGTGGAAACAGTAGCCAAAGTGTATCCATAAA

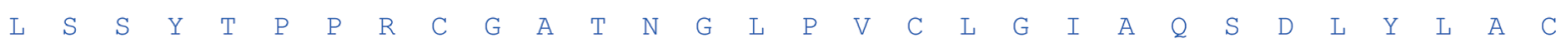

541 CCTGTCATCCTACACCCCTCCGAGGTGTGGAGCCACAAACGGCCTGCCAGTGTGTTTGGGGATTGCACAGAGCGACTTGTACCTTGCATG

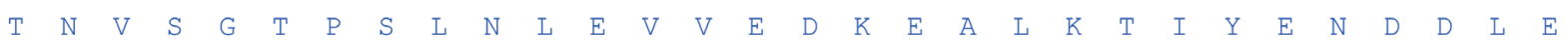

631 TACAAATGTTTCTGGAACTCCTAGTCTTAATCTAGAGGTGGTGGAGGACAAAGAGGCGCTGAAGACTATCTATGAGAACGATGACTTGGA $\begin{array}{llllllllllllllllllllllllllllllllllll}R & F & L & F & L & R & K & A & T & S & K & S & N & N & T & F & E & S & V & K & Y & P & G & W & F & I & S & T & A & K\end{array}$

721 GCGTTTCCTCTTCCTCCGAAAAGCTACTTCAAAATCGAATAACACCTTCGAATCAGTGAAGTACCCAGGCTGGTTCATCAGCACTGCTAA

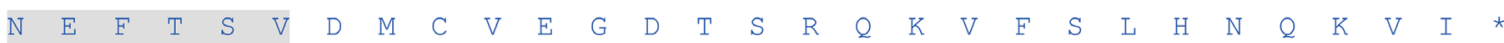

811 GAATGAATTCACGTCAGTGGACATGTGTGTTGAGGGGGACACCAGCCGTCAAAAAGTCTTTTCACTCCACAATCAGAAAGTAATCTAAga

901 atcagatttcattcacaatattagttttcccgaacgtatgtactaagtacagttatacatctggaggcttatgctgtgtttggatatttc

991 tcagttagagattgctgaccggcaatcatatcttgacccaagaagtaaaagttataaagttataatgtaagccaggaaattctggtg

1081 ttgtaacgtccaagacgtttaatacatgtattgttatttataaactctatttaacttgaacgtatttatatttgtaaaaatctattttc

1171 atgctaatgcttacaatgaaataaacaaacaatattaaaaaaaaaaaaaaaaaa

\section{B}

1 aaacaccagcagctgaactccagacacagtcttcactccgactccacctccttcaccgtcttcatcatctccagtgtctccggcgtctc $\begin{array}{llllllllllllllllllllll}M & N & S & R & I & V & G & V & C & \text { L } & \text { L } & \text { L } & \text { A } & \text { V } & \text { F } & \text { T } & \text { L } & \text { T } & \text { E } & G & \text { M } & S\end{array}$

91 cagtgtctgaagagtttctatcaggATGAACAGCAGAATCGTGGGGGTGTGTTTACTTTTGGCCGTCTTCACTCTGACCGAAGGTATGAG

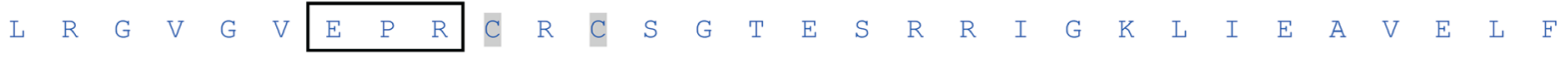

181 TCTGCGTGGTGTGGGTGTGGAACCCCGGTGCCGCTGCAGTGGAACCGAGAGTAGACGGATCGGCAAACTGATAGAGGCCGTGGAGCTCTT

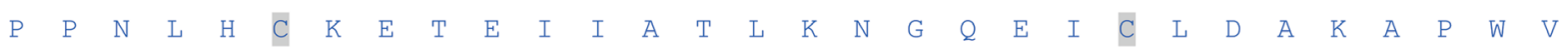

271 CCCCCCGAACCTCCACTGCAAAGAGACGGAGATCATAGCGACGCTAAAGAACGGTCAGGAGATCTGTCTGGACGCTAAAGCTCCGTGGGT $\begin{array}{llllllllllllllllllllll}M & K & I & T & E & K & I & M & A & N & R & S & P & *\end{array}$

361 CATGAAGATCACTGAGAAGATCATGGCCAACCGGTCACCCTAAggtcagacacaagatgttggtgccagaattgctccaattaatcatga 451 tggtcttgatgctggtcttcagattcttcttggcetctccattcctgccagcgcaggggtcattttgtctctcacgcttttgattatgc 541 tttgtactgtggccactggcgcttggaaacacttggatatggctttattgcttttcccetctcatgagcagccacagtgcacagaggtcc 631 atgctaaggtctctggttttagccgcgacttgcagttgcctactaatttacaagcagaactactgcatgagctgcactttcattatagct 721 gattagaatgttctagaacatggtagaaatgaccaggaccatttggaattgtatacaagctcatgtatatgcttatgaatggtatataca 811 catattttctaaataattcttgccaatttcaagaggcatgagtaactttggacatacattttttttggtaaaagtgtataaaaataaac 901 agaaatagttaaaatgtatctaacatttctagcacaatgttttatcatgttttatcccttgtttatgtcattttcagccaaagaaacct 991 attggtcaataagttcactataaatcgaaaaaaaaaaaaaaaaa

Figure 1 - Full-length cDNA sequence of pmIL-1 $\beta$ (A) and pmIL-8 (B) with deduced amino acids. The ORFs are underlined and shown in uppercase letters and the 5' and 3' UTRs are shown in lowercase letters. (A) The IL-1 family signature is highlighted in grey. Three instability motifs (ATTTA) are double underlined and the polyadenylation signal sequence (AATAAA) $19 \mathrm{nt}$ upstream the poly A tail is in bold. (B) The putative signal peptide is shown in red. The four conserved cysteines are highlighted in grey. The EPR motif is indicated by a black box. A single instability motif(ATTTA) is double underlined and the polyadenylation signal sequence (AATAAA) $21 \mathrm{nt}$ upstream the poly A tail is in bold. 
catfish. However, the cleavage position of this species has not yet been subjected to experimental functional validation (Wang et al., 2006).

The other regions of pmIL-1 $\beta$ were fairly conserved when compared to other vertebrates, especially in the predicted $\beta$-strands regions, with similarities ranging from $82.2 \%$ with red-bellied piranha to $25.9 \%$ with human IL- $1 \beta$. The interleukin-1 signature motif was identified at positions 231 to 251 in the characterized by the sequence FeSVkyPgwFISTakneftsV (Figure 2A).

The genomic region of pmIL-1 $\beta$ (GenBank accession number MT787041) showed 2139 nt in length and was structurally divided in seven exons and six introns, which is a similar structure to what is observed in the IL- $1 \beta$ from channel catfish, carp and human, but differed from zebrafish and rainbow trout, that showed only six exons and five introns. The seven exons of pacu IL- $1 \beta$ were $74,34,73,181,168$, 137 and $541 \mathrm{nt}$ in length, respectively. Similar to what was observed for almost all species analyzed, with the exception being zebrafish, the first exon of pacu IL- $1 \beta$ was entirely untranslated, with the start codon falling in the second exon (Figure 3A).

The phylogenetic analysis revealed that the closest related species with pacu IL-1 $\beta$ was the red-bellied-piranha, followed by the cave fish, both members of the Characiformes order. The non-characiform species that was more closely related to pacu IL- $1 \beta$ was the channel catfish, a member of the Siluriformes order. Furthermore, there was a clear separation between the clade composed by teleost species clade from the one containing other vertebrates (Figure 4A).

These variations in exon/intron organization, however, produced little effect in the similarities observed between the resulting IL-1 $\beta$ peptides, as evidenced by the results in the phylogenetic analysis (Figure 4A), in which the phylogenetic proximity of the species was more determinant in the clustering than the exon/intron genomic structure. The closest related species with pmIL-1 $\beta$ was the red-bellied-piranha, followed by the cave fish, both members of the Characiformes order. Similarly, zebrafish and rainbow trout clustered together with other cypriniforms and salmoniforms, respectively, despite having different exon/intron organization than their closest counterparts.

The full-length cDNA sequence of pmIL-8 (GenBank accession number MT787040) was composed of $1019 \mathrm{nt}$, subdivided in a 5' UTR of $115 \mathrm{nt}$, a 3' UTR of $616 \mathrm{nt}$ containing a single instability motif and a polyadenylation signal $21 \mathrm{nt}$ upstream the poly A tail and an ORF of $288 \mathrm{nt}$. The deduced protein sequence was composed of 95 amino acid residues with a theoretical molecular weight of $10.43 \mathrm{kDa}$ and an isoelectric point of 8.35 (Figure 1B).

The multiple amino acid sequence alignment comparing pmIL- 8 with other vertebrates showed that this protein is well conserved among vertebrates, with similarities varying from $85.3 \%$ with red-bellied piranha to $37.2 \%$ with human IL-8. The putative pmIL-8 protein showed all typical CXC chemokine features, including a 20-residue signal peptide at the $\mathrm{N}$-terminus region and four conserved cysteine residues at positions 32, 34, 58 and 74, with an arginine residue located between the first two cysteines, constituting the typical CXC chemokine structure (Baggiolini et al., 1995) (Figure 2B).

Two predicted disulfide bonds were identified connecting the sulfur atoms between $\mathrm{Cys}^{32}-\mathrm{Cys}^{58}$ and $\mathrm{Cys}^{34}$ $\mathrm{Cys}^{74}$. As observed for many other teleost IL-8, the ELR motif was not present in the pmIL-8, which showed a GluPro-Arg (EPR) motif in this position instead. The presence of this EPR motif was also observed in the predicted IL-8 sequences of the other characiform species included in this analysis, red-bellied piranha and cave fish (Figure 2B).

The pmIL-8 genomic region (GenBank accession number MT787042) was composed of 2210 nt structurally divided following the same pattern observed for all other vertebrates analyzed, with four exons and three introns. As expected for the untranslated regions, the 5' and 3' UTRs showed a higher degree of variation in length, which was also observed for the introns, that varied considerably among species (Figure 3B).

As observed for IL-1 $\beta$, the pacu IL- 8 phylogenetic analysis showed that this protein has a closer relationship with the sequences of the other characiforms, red-belliedpiranha and cave fish. A clear separation between the clades composed by teleost fish and the ones containing other vertebrates, with a further separation based on the orders of the fish was also observed for this gene (Figure 4B).

\section{Homology modeling of pacu IL-1 $\beta$ and IL-8}

For the modeling of the putative pacu IL-1 $\beta$ and IL-8, the amino acid sequences were analyzed using the SWISSMODEL workspace (Arnold et al., 2006) to identify suitable templates. The search identified 111 significant templates for IL- $1 \beta$ and 326 for IL- 8 that matched the target sequences. The crystal structure of human IL- $1 \beta$ and IL- 8 , that shared $30.20 \%$ and $36.76 \%$ sequence identity with the pacu sequences, respectively, were selected as templates. The QMEAN global quality scores for the models were -2.29 and -0.67 for IL- $1 \beta$ and IL- 8 respectively, indicating that the models had good structural quality.

Pacu IL-1 $\beta$ model showed a typical $\beta$-trefoil conformation resembling a barrel composed by twelve anti-parallel $\beta$-strands and three $\alpha$-helices with a shallow open face on one end and a closed face on the other, with a central hydrophobic cavity, which is the typical conformational structure of members of the IL-1 superfamily (Nicola, 1994) (Figure $5 \mathrm{~A})$.

The predicted pmIL- 8 monomeric 3D structure was composed by three anti-parallel $\beta$-strands and a single $\alpha$-helix at the C-terminus region, which is suggested to be involved in the formation of the IL- 8 receptor binding site, and is consistent with the known IL-8 structure of other teleosts and human (Clore et al., 1990; Wang et al., 2013; Herath et al., 2016). Another particular common feature of the tertiary 
A

pacu

red-bellied piranha

cave fish

sea bass

zebrafish

carp

tilapia

tilapia

salmon

channel catfish

chicken

human

pacu

red-bellied piranha

cave fish

sea bass

zebrafish

carp

trout

salmon

channel catfish

chicken

human

pacu

red-bellied piranha

cave fish

sea bass

zebrafish

carp

trout

tilapia

salmon

channel catfish

chicken

human

pacu

red-bellied piranha

cave fish

sea bass

zebrafish

carp

tilapia

salmon

channel catfish

chicken

human

M-ADK-DM----LLLESFF--DSAFESDEMDCDELDCSDPLAMSGRCAL---HRGLRIE--IT--EQPHSMRQVANFVIALNKF-K---H 71 M-SDK-DL----LLLESFFENDSAFESDETDFDEVDCSYPLAMSGRCNL---HNGLWIE--IS--DQPHSMKOVANVIIASHRF-K---H 73 M-EDA-RM----LLLECSSESDSTFESDEMDFDELDCSDPLAMSGRCDI---HRGLRIE--IS--OHPHSMRKVANIVTGLORL-OKFRH 76 ----_---_---_--_---MESEMKC---------NMSEMWRSKM---PQGLDLE--IT--HHPLTMRRVVNLI IAMERL-K---G 47 M-ACG-QYEV-TIAPKNLWETDGAVYSDS---DEMDCSDPLAMSYRCDM---HEGIRLG--MW--TSQHKMKQLVNVIIALNRM-K---H 73 M-ALHGR----YILPSDALETDLI-YPDSAGFDE PDCPDQLCMMCQCDM---HKDIKLE--LS--PHPHSMRKVVNIVIAVEKL-K---H 73 MDFKMSY - IK-NG M-DRT-ELYKRI I LFSRSNYTDMEFESNYSL-IK-NT--SESKAWSSKL---PQGLDLE--VS--HHPITMRHIANLIIAMERL-K---G 73 M-DDK-DL----LTLERSFDSDCGFDSDAMDF DE LDCSDPLAMSGRCDL---HEGLRIE--VT--KE PLSMRQVANVVIALQRL-K---L 73 MAFVP-DLD----VLESSSLSEETFY-GP----SC-----LCLQKKPRLDSEHTTVDVQVTVRKGRGARSFRRAAVLVVAMTKLLR---R 72 MAEVP-ELASE-MMAYYSGNEDDLFFEAD-GPKQMKCS--FQDLDLCPL---DGGIQLRIS--DHHYSKGFRQAASVVVAMDKL-R---K 76

$$
\text { : : } \quad::: \text { : : : : : : : }
$$

T--OKVQ-STEFTDNELFNI ILERVIEESVVTTVHCESLKT-----YNKODRVIQCTVCDSLKKSLVQFO----GGRTLLAVTLKGGNSS 149 T--QKEQ-STEFTNHE LFNI I LES I IEESAVTTVHCESLKT-----YNKQDKVVQCSMCDGLKKSLVQFQ----GGHTLLAVTLKAGNSS 151 A--EKVSRSTEFTEHELLNIILESVVEETVVMRLSCDSPVT-----YSKQDKELQCTVCDNLQKRLVHSE----GDPYLLAVTLKGGNQS 155 FSSE-TLMSTEFRDENLLNIMLESIVEEKIVFERGTTPTAQ-----YSKR-REVQCSVTDSEKRSLVLVP----NSMELHAVMLQGGSDR 126 I--KP-O-STEFGEKEVLDMLMANVIQEREVNVVDS--VPS-----YTKTKNVLQCTICDOYKKSLVRSG----GS PHLQAVTLRAGSSD 148 I--KKMS-SGKFSODALLNI I LENVIEERLVKPLNA--TOT-----YRKTTRTLOCSVCDKYKKTLVOSNKLTNODLHLKAVTLSAGTIQ 153 G--EGVTMGTEFKDKDLLNFLLESAVEEHIVLELESAPPASRRAAGFSST-SOYECSVTDSENKCWVLMN----EAMELHAMMLOGGSSY 136 SNSE-PVLSTEFQDESLLS IMLES IVEEHS I IERTAGP-PQ-----FTSR-DEIECTVTDSQKRSLVLLH----SSMELHAVMLQGGSED 124 G--EGVTMGTE FKDKDLLNFLLESAVEEH IVLELESAPPT SRREAGFSST-SQYECSVTDSENKCWVLMS----EAMELHAMMLQGGSGY 156 T--QNIQ-STEFTDQELFNVFIENVIEESMVINLKCTESKS-----YSLQDKVVRCTICDKSKRALVQRE----KLPILLAFTLKGGNKD 151 P-----R-SRDFADSDL-SALIEEVFEPVTFORLESSYAGA---PAFRY-TRSOSFDIFDINOKCFVLES-----PTQLVALHLQGPSSS 146 M--LVPC-PQTFQENDLSTFFPFIFEEEPIFFDTWDNEAYV-----HDAPVRSLNCTLRDSQQKSLVMSG-----PYELKALHLQGQDME 153

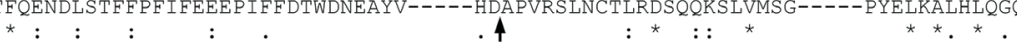

QSVSINLSSYTPPR--C-G-ATNGLPVCLGIAQSDLYLACTNV-SG-TPSLNLEVVEDKEALKTIYENDDLERFLFLRKATSKSNN-TFE 232 RSVSINLSPYTTPR--C-G-ATVGLPVCLGIAQSDLYLACTNV-SG-TPSLNLEVVEDKEALKTIYENDDMERFLFRRKVTAKSIN-TFE 234 QSVRINLSTYASPS--C-N-STKGQPVCLGIAKSNLYLSCTESDSG-SPHLSLEEVKNKEELKMIRGEDGLKRFLFLRSVKGGSVN-TEE 23@ CKVOLNMSTYLDRT--P---SAEAOTVALGIKGTNYYLSCHKD-GE-EPTLHLEVV-DKASLANITSDSDMVRFLFYKODSGLNIS-TLT 207 LKVRFSMSTYASPS--A-P-ATSAQPVCLGISKSNLYLACCPAEGSTSPHLVLKEISGSLETIKAGDPNGYDQLLFERKETGSSIN-TEE 233 YKVQFSMMTYVSS---A-Q-QNNGQPVCLGISNSNLYIACTQSG-GSPPVLLLKEVSGPLNTITADDPNGYDSLLFFRKETGTAYN-TFE 236 HKVHLNLSSYVTPV--P-I-ETEARPVALGIKGSNLYLSCSKS-GG-RPTLHLEEVADKDQLKS ISQQSDMVRFLFYRRNTGVDIS-TLE 21@ RKVHLNMSTYAHPT--P---IAETRPVALGIKGTNLYLSCHKD-DD-KPTLHLEEVTDKNSLSRISAESDMVRFLFYKRDTGVSIS-TLM $20 \mathrm{\epsilon}$ HKVHLNLSTYVTPV--P-I-ETKARPVALGIKGSNLYLSCSKS-GG-RPTLHLEEVANKEQLKS ISQQSDMVRFLFYRRNTGVDIS-TLE 23@ NKAWFNLSAYTPPN--C-TENTKGOPVCLGIVKTNLFLSCTLE-NE-TPFLGLEEVKDKERLKS IOENDGMERFLFFRNGTGDSLN-TFE 235 QKVRLNIALYRPRGPRGSA-GTGQMPVALGIKGYKLYMSCVMS-GT-EPTLQLEEADVMRDIDSV----ELTRFIFYRLDSPTEGTTREE 229 QQVVFSMS-FVQ----GEE-SNDKIPVALGLKEKNLYLSCVLK-DD-KPTLQLESVDPKNYPKKK----MEKRFVFNKIEINNKLE--FE $22 \mathrm{C}$

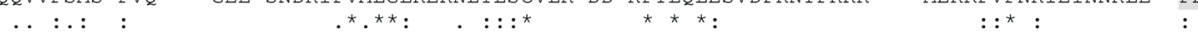

SVKYPGWFISTAK--NEFTSVDMCVEGDTSRQKVFSLHNQKV-------------I 273 SIKYPGWFISTAR--NENMPVDMCVEEDSHROKVFSIHNQKV-------------I 275 SARFPGWFISTAT--EDDQPVEMCGEADTSRQRVFTLLP--------------- 276 SVPFSNWYIST--AEENNRPVQMCQESA-RRHRAFNIDNLKVDPTTEDQVCPLLNGQ 261 SVKCPGWFISTAY--EDSQMVEMDRK-DTERI INFELQDKVR------------I 273 SVKYPGWFISTAF--DDWKRVEMSQV-PTDRTTDFTLQD----------------- 272 SASFGNWFISTDMQQDYTKPVDMCQKAAPNRLTTFTIQRH---------------N 260 SVRYPNWYIST--AODDDQVVEVCOETA-PRYRSFNIOLO-_-_-_-_-_-_-_-S 244 SAGFRNWF ISTDMQQDNTKPVDMCQKAAPNRLTTFTIQRH---

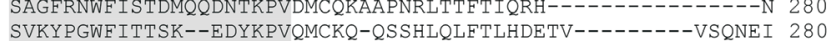
SAAFPGWFICTSL--QPRQPVGITNQPDQVNIATYKLSG--R------------- 267 SAQFPNWYISTSQ--AENMPVFLGGTKGGQDITDFTMQEVSS------------- 269

B

pacu

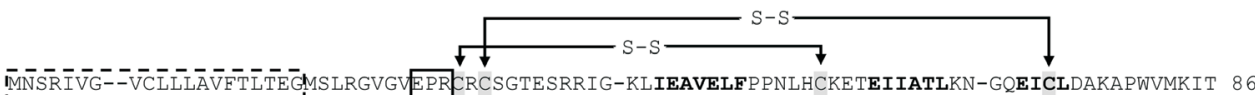
MNSRILG--VCLLLAVFPLTGMSIPGMGVEPRCRCSGTESKRIG-RLIESVELFPPNPHCKETEIIATLKNTGQEICLDTTAPWVKKVI 87 MKCIVVC--VSLLTVFFTLAEGMSLHGLGVEPRCRCSGTESRRIG-KLIESIELFPPNPHCKDTEIIATLKSNGQEICLDPKAPWVTKVI 87 MNCKIFLVSLIIFLGFLTIGEGMSLRGLGVDPRCRCIETESRRIG-KHIESVELFPPNSHCKDTEIIATLKITGKEICLDPTAPWVKKVI 89 MHCKIFLVSVIVFLGFLTTGEGMSLRGLGVDPR RCIETESRRIG-KHIESVELFPPSSHCKDTEIIATLKISGKEICLDPTAPWVKKVI 89

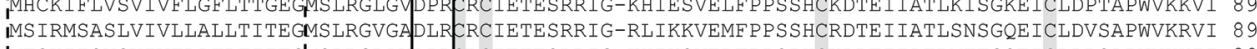
MTSKIISVCVIVFLAFLTIIEGMSLRGLAVDPR RCIETESRRIG-KHIKSVELFPPSPHCKDLEIIATLMTTGQEICLDPSAPWVKKII 89 MNGKLG-AVLALLLVSAALSQGRTLVKMGNELREOCISTHSKF IHPKSIQDVKLTPSGPHCKNVEIIATLKD-GREVCLDPTAPWVQLIV 88

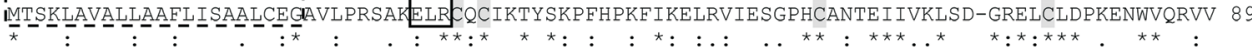

zebrafish

hicken

pacu

EKIMANRS------P 95

Diranha EKIMASRS------P 96

EKILAKRS------S 96

goldfish EKIIANKA------P 98

carp

salmon

chicken

EKIIANKA------P 98

KKMLANN------K 97

DRIIVKK-------P 97

KALMAKAQLNSDAPL 103

EKELKRAE-----NS 99

. : :

Figure 2 - Multiple alignment of the predicted amino acid sequence of pmIL- $1 \beta$ and pmIL- 8 with other known vertebrates IL- $1 \beta$ and IL- 8 proteins. Identical (*) and similar (: or .) residues are indicated. (A) Putative caspase-1 cleavage sites are indicated with a downward arrow head for pacu IL-1 $\beta$ and with an upward arrow for human IL-1 $\beta$. Conserved $\beta$-strand forming residues in the mature peptide are in bold. IL-1 family signature is indicated by grey shadow. (B) Signal peptide is indicated by a dotted box. The four conserved cysteines are highlighted by grey shadows. The EPR motif is indicated by a black box. Conserved $\beta$-strand forming residues in the mature peptide are in bold. Disulfide bonds are indicated by lines connecting sulfur atoms of cysteine residues $(\mathrm{S}-\mathrm{S})$. 
A

Pacu IL-1 $\beta$

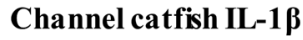
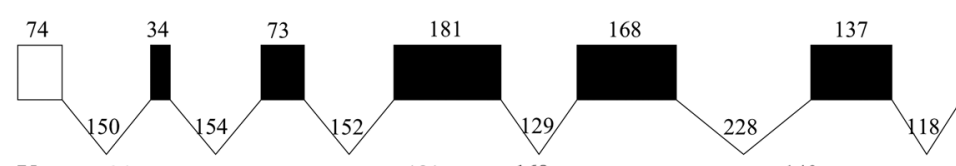

231

310

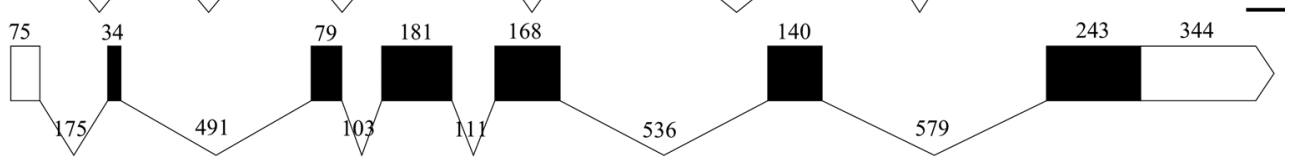

Zebrafish IL-1 $\beta$

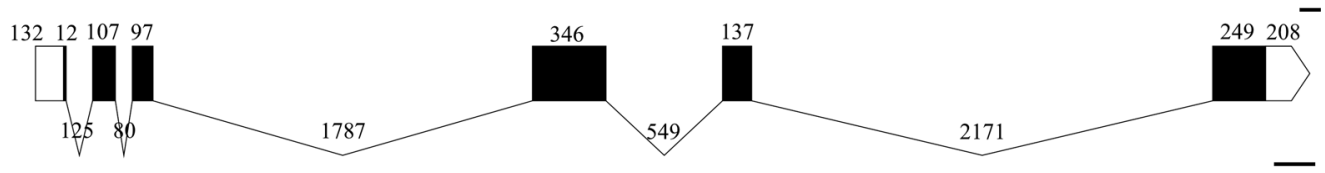

Rainbow trout IL-1 $\beta$

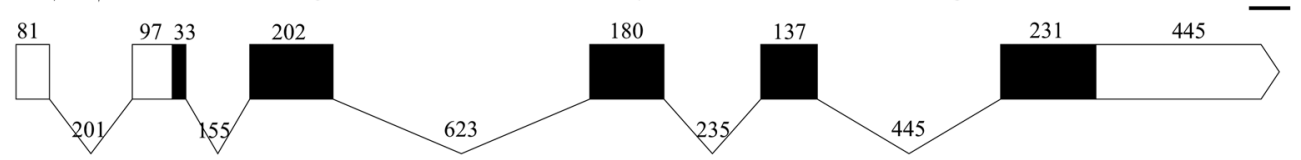

Carp IL-1 $\beta$

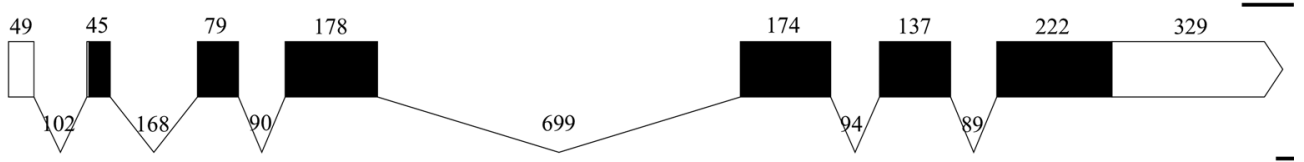

Human IL-1 $\beta$

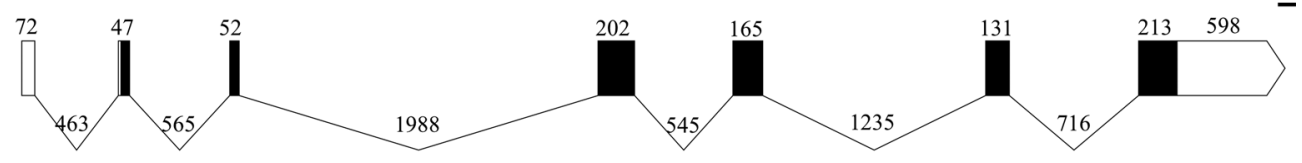

B

Pacu IL-8

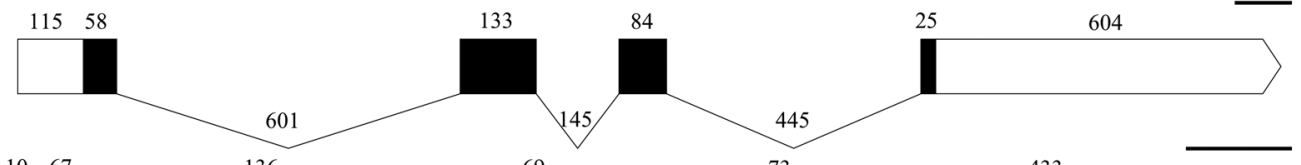

Channel catfish IL-8

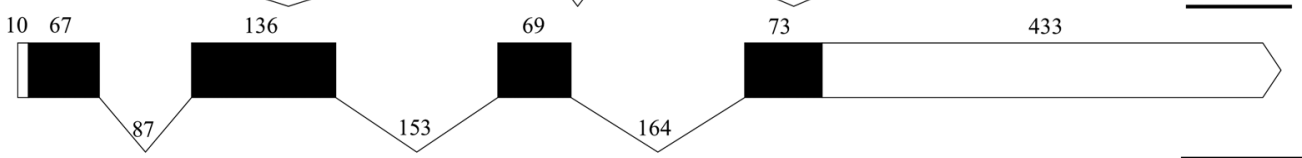

Zebrafish IL-8

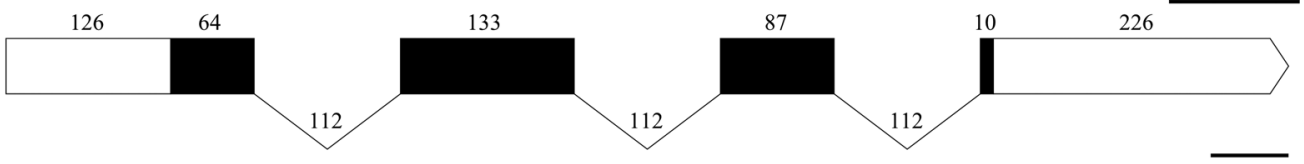

Rainbow trout IL-8

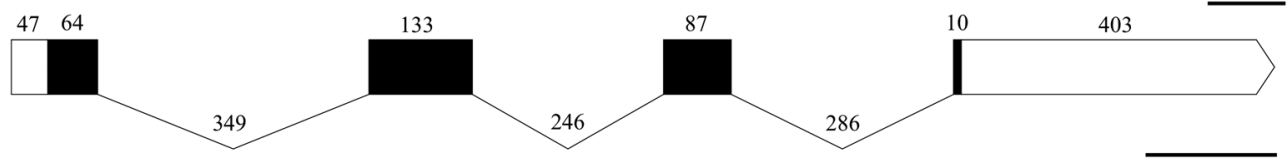

Grass carp IL-8

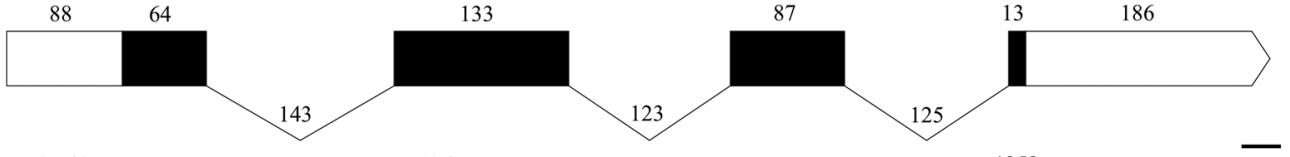

Human IL-8

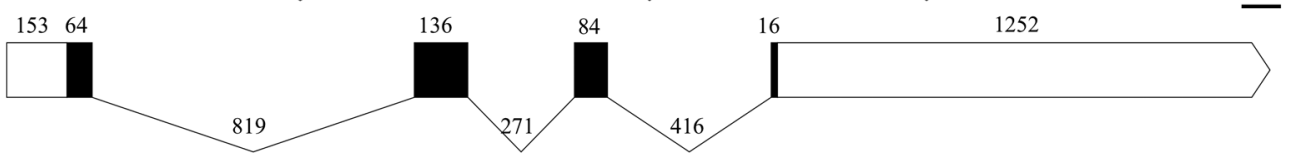

Figure 3 - Schematic representations of exon-intron arrangement of pmIL-1 $\beta$ (A) and pmIL-8 (B). PmIL-1 $\beta$ was compared with the sequences of channel catfish (Ictalurus punctatus DQ157743), zebrafish (Danio rerio FM213388), raibow trout (Oncorhyncus mykiss AJ004821), carp (Cyprinus carpio AJ245635) and human (Homo sapiens M15840) and pacu IL-8 was compared with the sequences of channel catfish (Ictalurus punctatus AY145142), zebrafish (Danio rerio NC_007112), raibow trout (Oncorhyncus mykiss AY160987), grass carp (Ctenopharyngodon idellus JN663841) and human (Homo sapiens NG_029889). Exons are indicated by boxes and introns by v-shaped lines. White areas indicate untranslated regions (UTRs). The size of each exon and intron is given (in base pairs) above the boxes and bellow the lines, respectively. Scale bars $=100$ base pairs. 
A
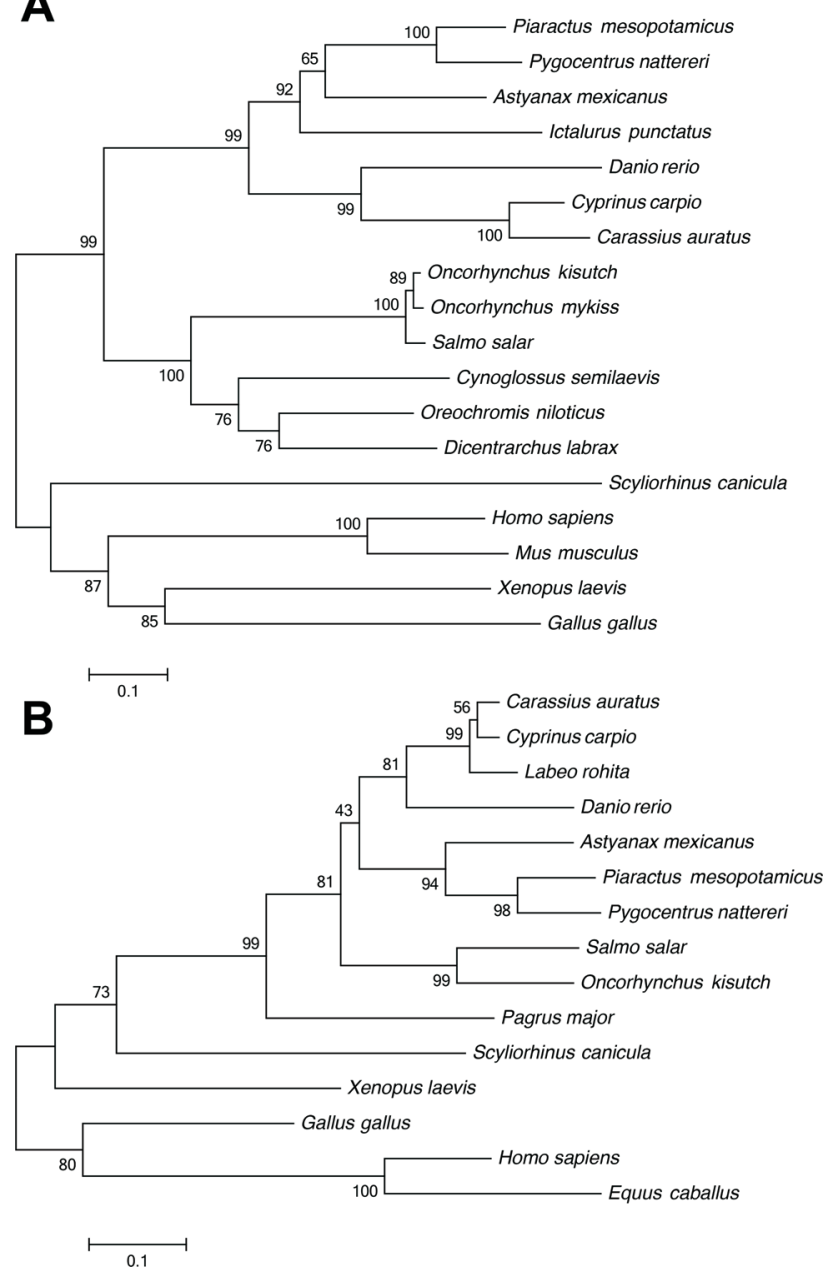

Figure 4 - Neighbor Joining phylogenetic analysis comparing the complete amino acid sequences of pmIL-1 $\beta$ (A) with Pygocentrus nattereri XP 017549212, Astyanax mexicanus XP 022536473, Ictalurus punctatus NP_001187148, Danio rerio AAQ16563, Cyprinus carpio CAC19888, Carassius auratus CAD12102, Oncorhynchus kisutch XP 020331449, Oncorhynchus mykiss CAC83518, Salmo salar XP 014025954, Cynoglossus semilaevis ACU55137, Oreochromis niloticus XP 019221386, Dicentrarchus labrax CAC80553, Scyliorhinus canicula CAC80866, Homo sapiens NP_000567, Mus musculus EDL28238, Xenopus laevis AAI70521 and Gallus gallus NP 989855 and the sequence of sequence of pmIL-8 (B) with Carassius auratus AGG11027, Cyprinus carpio ABS70451, Labeo rohita ADJ53042, Danio rerio XP_009305130, Astyanax mexicanus XP_007229345, Pygocentrus nattereri XP_017541078, Salmo salar NP_001134182, Oncorhynchus kisutch XP_020360239, Pagrus major ADK35756, Scyliorhinus canicula CAD91126, Xenopus laevis AEB96252, Gallus gallus ADU60331, Homo sapiens AAH13615 and Equus caballus AAO37764. Numbers at branching points indicate bootstrap confidence levels for 1000 repetitions. Bar represents 0.1 amino acid substitutions per site.

structure of pmIL-8 that is shared among many other vertebrates is the occurrence of two putative disulfide bonds between $\mathrm{Cys}^{32}{ }^{32} \mathrm{Cys}^{58}$ and $\mathrm{Cys}^{34}-\mathrm{Cys}^{74}$, which are responsible to stabilize the protein fold (Berkamp et al., 2017) (Figure 5B).

\section{Tissue distribution of pacu IL-1 $\beta$ and IL- 8 transcripts}

The tissue distribution of pmIL- $1 \beta$ and pmIL- 8 under physiological conditions was investigated by qPCR in the

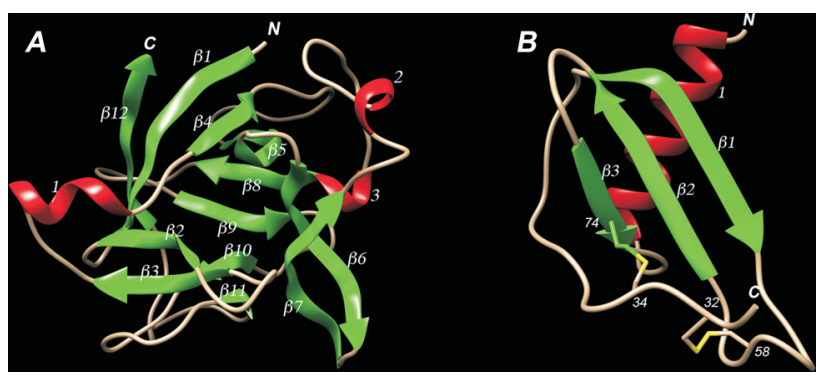

Figure 5 - Homology based three-dimensional modeling of pmIL-1 $\beta$ (A) and pmIL-8 (B) presented as ribbon diagrams. Amino- and carboxyltermini regions are indicated with the letters "N" and "C", respectively. (A) predicted tertiaty structure of pmIL- $1 \beta$ monomer showing 12 conserved $\beta$-strands (green) and $3 \alpha$-helices (red). (B) predicted terciary structure of pmIL- 8 monomer showing $3 \beta$-strands (green), $1 \alpha$-helix (red) and 2 putative disulfide bonds (yellow) between $\mathrm{Cys}^{32}-\mathrm{Cys}^{58}$ and $\mathrm{Cys}^{34}-\mathrm{Cys}^{74}$.

liver, spleen, head kidney, gill, intestine and skin of healthy pacus. Both genes showed constitutive expression in all tissues analyzed with variable amounts of mRNA transcripts. PmIL-1 $\beta$ showed the highest expression level in the spleen, which was 65.1-fold higher than what was observed in the liver, which was the organ with the lowest IL-1 $\beta$ mRNA levels. The other tissues showed consistent lower levels of IL-1 $\beta$ transcripts when compared to the spleen and liver (Figure 6A). For IL-8, constitutive expression was also detected in all tissues analyzed, with the highest expression levels observed in the liver, followed by gill, spleen, skin, head kidney, and with intestine being the organ where this gene was less transcribed (Figure 6B).

\section{Transcriptional response of $P$. mesopotamicus IL-1 $\beta$} and IL-8 following bacterial infection

To investigate the involvement of the cytokines IL- $\beta$ and IL-8 under pathogenic conditions in pacu, fish were experimentally infected with a pathogenic strain of $A$. dhakensis and transcripts were quantified in the liver, spleen and head kidney at 12, 24 and $48 \mathrm{~h}$ post-infection by qPCR.

PmIL-1 $\beta$ showed no significant expression variations in the liver at any of the analyzed periods. On the other hand, significant up-regulation was observed at $12 \mathrm{~h}$ post-infection in the spleen $(p<0.0001)$ and head kidney $(p=0.0441)$, where a 3.5 and 2.2 -fold transcript increase, respectively, was observed when compared to the control groups. After 24 $\mathrm{h}$, transcript levels did not differ in comparison to the control groups in any of the organs analyzed (Figure 7A).

As observed for pmIL-1 $\beta$, pmIL-8 showed a significant up-regulation in the spleen $(p=0.0331)$ and in the head kidney $(p=0.0319)$ at $12 \mathrm{~h}$ post-infection, again with the first showing higher regulations after the bacterial challenge with 3.65 and 1.73 -fold transcript increase, respectively. At $24 \mathrm{~h}$ post-infection, on the other hand, this gene showed significant down-regulation in the liver $(p=0.0159)$ and in the head kidney $(p=0.0043)$ to nearly half the expression of the control groups. No expression changes were observed at 48 


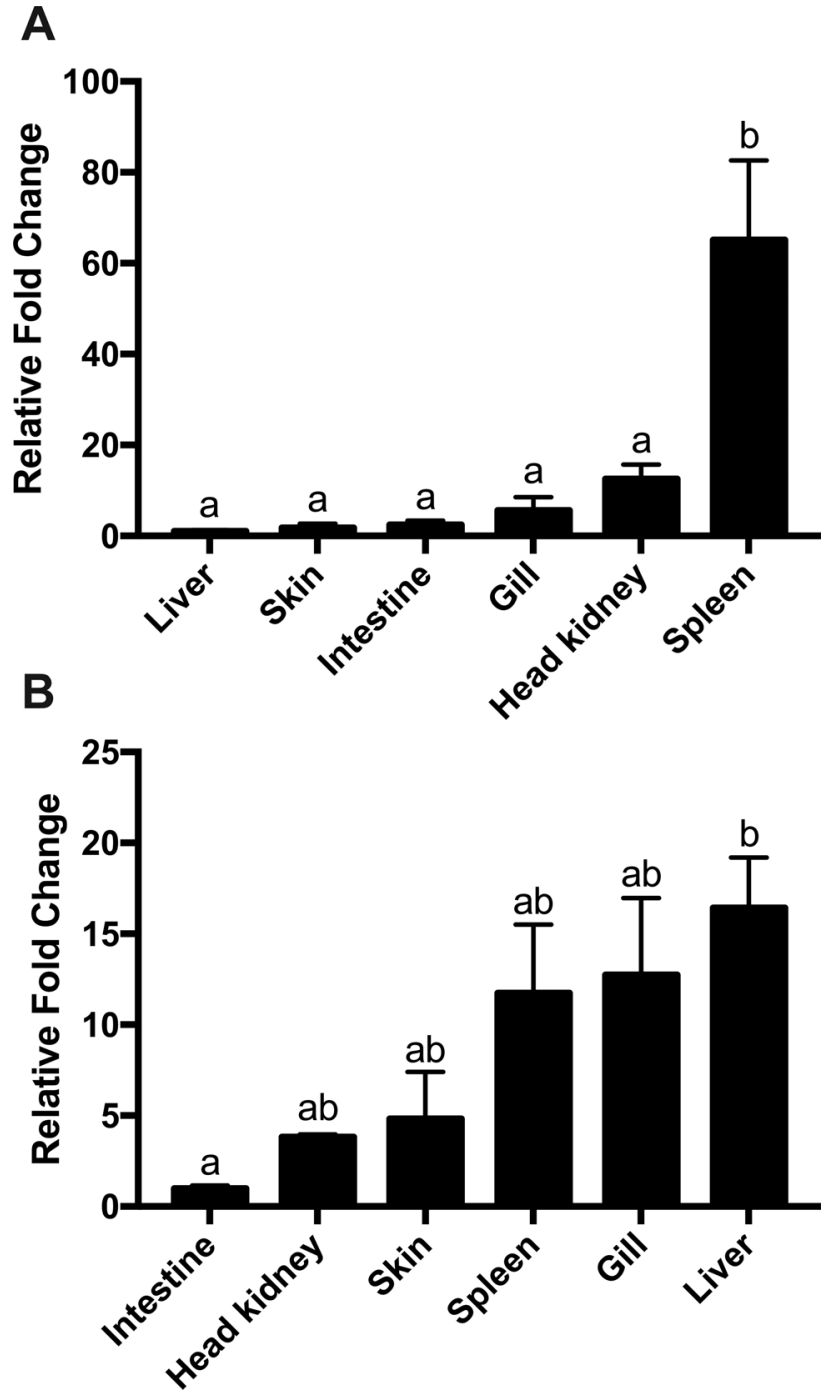

Figure 6 - Tissue distribution of mRNA expression of pmIL-1 $\beta$ (A) and pmIL-8 (B) in the liver, spleen, head kidney, gill, intestine and skin of healthy uninfected pacus. Relative mRNA expression is expressed as fold change relative to liver for IL- $1 \beta$ and to intestine for IL- 8 calculated using $\beta$-actin as endogenous reference. Data are presented as mean $(\operatorname{SEM}(n=$ $5)$. Levels not connected by same latter are significantly different in Tukey's test $(p \leq 0.05)$.

$h$ post-infection for any of the genes in any of the three organs (Figure 7B).

\section{Discussion}

In the present study, cDNA and genomic DNA sequences of the pro-inflammatory cytokines IL-1 $\beta$ and IL-8 from pacu were characterized and their amino acid sequence, as well as their tertiary structure, were deduced. Furthermore, the transcriptional profile of these proteins was investigated under physiological and pathological conditions.

The genomic structure analysis of pmIL- $1 \beta$ revealed that, even though pacu and human only shared $25.9 \%$ identity between their IL-1 $\beta$ amino acid sequences, the exon/intron organization was the same in both species. On the other hand, other fish species with higher amino acid similarity to pmIL-1 $\beta$, such as zebrafish and rainbow trout, showed different exon/intron organization, with a $6 / 5$ exon/intron structure. This can be explained by the fact that exon/intron structure variations are usually caused by exon fusion, which usually occurs mainly at the 5' end of the gene, away from the region encoding the biologically active mature peptide (Secombes et al., 2011).

The deduced pmIL- $1 \beta$ precursor peptide was similar in length to the sequences of several vertebrates, with roughly 270 amino acid residues in length that contained the interleukin-1 signature motif is in accordance to the proposed consensus signature for vertebrates [FCL]-X-S[ASLV]-x(2)-[PSK]-x(2)-[FYLIV]-[LIV]-[SCAT]-T-x(7)[LIVMK] (Lee et al., 2006). A putative caspase-1 cleavage site was also detected at $\mathrm{Asp}^{114}$ producing a putative mature peptide with a molecular weight of $17.21 \mathrm{kDa}$. This molecular weight is very similar to what is typically observed in mammals, in which IL-1 $\beta$ is known to be expressed as an inactive precursor (proIL-1 $\beta$ ) with a molecular weight of about $31 \mathrm{kDa}$ and then cleaved by the enzyme caspase- $1 \mathrm{im}-$ mediately after a conserved aspartic acid located between positions 113 and 117 to form the mature biologically active form with a molecular weight of approximately $17 \mathrm{kDa}$ (Zou et al., 1999; Zhang et al., 2017).

In most teleost species, the cleavage mechanism involved in the processing of pro-IL-1 $\beta$ into the mature peptide is not fully elucidated, since a caspase- 1 cleavage site identical to what is observed in mammalian IL-1 $\beta$ has not been identified in any fish species so far (Hong et al., 2004; Pelegrin et al., 2004). However, there are some fish species, such as sea bass, in which IL-1 $\beta$ precursor has been shown to be specifically cleaved by caspase- 1 in a different aspartic acid residue than mammalian IL- $1 \beta$ to produce the $18 \mathrm{kDa}$ biologically active mature peptide by cleavage of its proform at $\mathrm{Asp}^{100}$ (Reis et al., 2012). When comparing the IL-1 $\beta$ sequences of pacu and sea bass, a conserved aspartic acid $\left(\mathrm{Asp}^{123}\right)$ was observed in the same position as the putative cleavage position of sea bass, which would suggest that this is in fact the cleavage site.

However, in the homology modeling analysis using human IL-1 $\beta$ as template, this position was located in a beta sheet-forming region, which has important structural function in mammalian and chicken IL-1 $\beta$. For this reason, although further functional experiments are still needed to confirm the actual caspase- 1 cleavage site in pmIL-1 $\beta$, $\operatorname{Asp}^{114}$ was considered more likely to undergo cleavage by caspase-1 than $\mathrm{Asp}^{123}$. It is important to point out that sea bass IL- $1 \beta$ does not have a homologous aspartate in the position of $\mathrm{pmAsp}^{114}$, which has led to the deduction that, for this species, Asp ${ }^{100}$ is the caspase-1 cleavage site (Reis et al., 2012).

Moreover, the pmIL-1 $\beta$ showed a typical $\beta$-trefoil structure consisting of twelve antiparallel $\beta$-strands and three $\alpha$-helices, forming a barrel-like structure with a central hydrophobic cavity, which is the typical conformational 

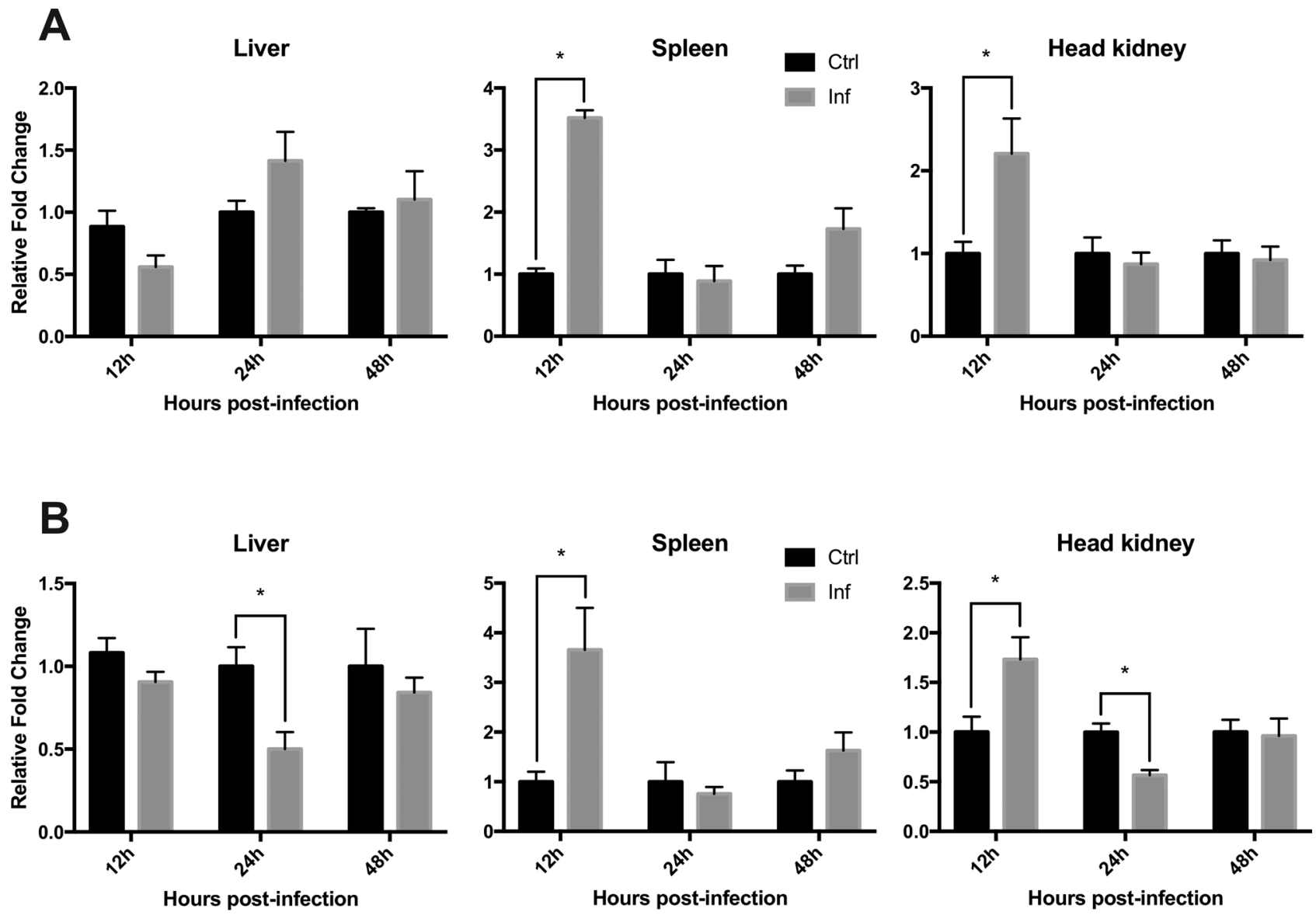

Figure 7 - Transcriptional expression levels of pmIL-1 $\beta$ (A) and pmIL-8 (B) in the liver, spleen and head kidney at 12, 24 and $48 \mathrm{~h}$ post-infection with $A$. dhakensis. Relative mRNA expression is expressed as fold change to the control samples at the same time point and was calculated using $\beta$-actin as endogenous reference. Data are presented as mean $(\operatorname{SEM}(n=5)$. Asterisks indicate significant differences between control $(\mathrm{Ctrl})$ and infected $(\mathrm{Inf})$ groups in Student's $t$-test $(p \leq 0.05)$.

structure of members of the IL-1 superfamily. Even though this hydrophobic cavity is not directly implied to any functional aspect of its pro-inflammatory properties, it though to probably play a critical role in maintaining the structural integrity of the protein (Cheng et al., 2011). It is important to point out that, this typical structure only is observed when considering Asp ${ }^{114}$ as the caspase-1 cleavage site, similar to what is observed in mammals, and not $\mathrm{Asp}^{123}$, which is in the same position as the cleavage site observed in sea bass IL- $1 \beta$. In this case, only eleven $\beta$-sheets would be observed and consequent destabilization of the other C-terminal betasheet forming segments could occur (Reis et al., 2012).

The genomic DNA sequence of pmIL-8, composed of four exons and three introns, was the same observed for all fish species analyzed in the present study, as well as for humans. The exon lengths, as well as the overall amino acid sequence structure of pmIL-8, were also highly similar to other vertebrates, indicating that this chemokine is evolutionarily conserved across vertebrates (Berkamp et al., 2017).

The deduced amino acid sequence of pacu IL-8 showed a signal peptide and four conserved cysteine residues, which are consistent with the typical CXC chemokine structure and containing, as observed for most species, less than one hundred amino acid residues (Baggiolini et al., 1995; Berkamp et al., 2017). The amino acid arginine observed between the first two cysteine residues is also conserved in almost all teleosts with few exceptions, such as the large yellow croaker (Larimichthys crocea), which has a glutamine in this position (Wang et al., 2013).

In mammalian IL-8, the ELR motif is usually observed right before the CXC motif and is recognized as being involved in the neutrophil attraction properties of this chemokine (Sabat and Schwartz, 2004). In general, this motif is vastly diverse among IL-8 from teleosts, with some species containing the same ELR motif found in mammals, such as haddock and Atlantic cod, while others have a SLH, PLR, DLR or LLR motif in this position (Lee et al., 2001; Fujiki et al., 2003; Corripio-Miyar et al., 2007; Harun et al., 2008; Seppola et al., 2008; Oehlers et al., 2010; Li and Yao, 2013; Chu et al., 2014). PmIL-8, however, did not show any of the aforementioned motifs, showing a unique EPR motif in this position, which was shared only by the species red-bellied piranha and cave fish, also members of the Characiformes order, suggesting that this motif is conserved only among representatives of this particular order. 
Even though teleost IL-8 usually do not have a classical ELR motif, it has already been shown that this cytokine still exerts a chemoattractant effect on neutrophils and mononuclear leukocytes, and induces neutrophil infiltration, which indicates that this motif is not strictly necessary to produce its chemoattractant and pro-inflammatory activities in fish (Sun et al., 2011; van der Aa et al., 2012; Wang et al., 2013). This was observed in the present study, where a significant upregulation of this protein in bacteria-infected fish was observed (further discussed below), indicating that, even without the presence of the ELR motif, pmIL-8 is still highly involved in the initiation of the inflammatory process. Nevertheless, the exact influence of each of the motifs in the chemoattractant effect in teleost IL-8 still needs further investigations.

The molecular structure of pmIL- 8 was composed of three antiparallel $\beta$-strands as well as a single $\alpha$-helix, which is suggested to be involved in the formation of the IL-8 receptor binding site, and is consistent with the known IL-8 structure of other teleosts and humans (Clore et al., 1990; Wang et al., 2013; Herath et al., 2016). Another particular common feature of the tertiary structure of pacu IL- 8 that is shared among many other vertebrates is the occurrence of two disulfide bonds linking the conserved cysteines that stabilize the protein fold (Berkamp et al., 2017). The observed structural similarity of pmIL-8 with other previously described IL- 8 corroborates the idea that this protein shares similar biological function with other vertebrate counterparts.

The tissue distribution of pmIL- $1 \beta$ and pmIL- 8 transcripts in the liver, spleen, head kidney, gills, intestine and skin of healthy pacus showed that both cytokines are constitutively expressed in all six tissues examined, with higher levels of IL- $1 \beta$ being observed in the spleen, followed by the head kidney, and with similar expression level among all other tissues, whereas the highest transcript amounts of IL-8 was observed in the liver, followed closely by gill, spleen, skin and head kidney.

Such pleotropic distribution of IL- $1 \beta$ and IL- 8 across several tissues of healthy fish has already been described for other teleost species (Pelegrin et al., 2001; Scapigliati et al., 2001; Engelsma et al., 2003; Chen et al., 2005; Qiu et al., 2009; Wang et al., 2013), suggesting that these cytokines are probably involved in biological processes other than the response to pathogenic infections. Furthermore, the distribution pattern of these genes is not consistent in all fish species, which indicates that interleukin mRNA expression profile is species-specific (Herath et al., 2016).

In the analysis investigating the transcriptional effects of the bacterial infection with $A$. dhakensis, it was clearly observed that, for both genes, the spleen was the organ that showed higher up-regulation in response to the bacterial infection, followed by the head kidney. This could be explained by a higher leukocyte production in the spleen, or it could only reflect the natural progression of the infection throughout the organs. A similar transcriptional behavior was observed for IL-1 $\beta$ and IL- 8 under bacterial- and/or
LPS-stimulation in channel catfish (Chen et al., 2005; Wang et al., 2006), sea bream (Pelegrin et al., 2004), black rockfish (Herath et al., 2016) and Japanese sea perch (Qiu et al., 2009), in which high transcript upregulation was observed in the spleen and head kidney. These results were to be expected, given that this cytokine is highly produced by leukocytes in the early phases of the inflammatory process (Dinarello, 2010), which in the case of Aeromonas infections in $P$. mesopotamicus, takes place at around $12 \mathrm{~h}$ postinfection.

Similar to what was observed in the present study, where a significant decrease in pmIL- 8 transcript levels was observed in the liver and head kidney, a significant downregulation of IL-8 was observed in the spleen and blood cells of black rockfish stimulated with Streptococcus iniae and poly I:C after $24 \mathrm{~h}$ post-stimulation and following an initial upregulation (Herath et al., 2016). This is probably due to the activation of anti-inflammatory pathways of monocytes and macrophages which are activated to prevent tissue damage during acute inflammation, mainly by the production of anti-inflammatory cytokines, such as interleukin-10, which is known to induce down-regulation of pro-inflammatory cytokines like IL-8 (Sabat et al., 2010).

Also indicated by the findings of the present study and for many other teleost species, the expression profiles of IL-8 under inflammation indicates that the presence of the ELR motif apparently is not strictly necessary for it to exert chemotactic activity in the inflammatory responses against pathogens in teleosts. On the other hand, the other important function related to the presence of the ELR motif, which is the formation of new blood vessels known as angiogenesis, is not fully explored in fish. (Strieter et al., 1995) have shown that, in mammals, CXC chemokines that contain the ELR motif showed potent angiogenic activity, whereas CXC chemokines lacking this motif where highly angiostatic. Therefore, further studies are needed to evaluate the angiogenic/angiostatic properties of the EPR motif observed in pacu IL-8 in comparison to the classical ELR motif found in mammals.

Taken together, the results obtained in the present study suggest that IL- $1 \beta$ and IL- 8 are involved in the early response against bacterial pathogens in pacu, which, during bacterial infections, takes less then 12 hours to initiate, and since the inflammatory process occurs as a cytokine activation cascade, after this period, their expression decreases to physiological levels and other proteins may take place in the maintenance of the inflammatory process (Secombes et al., 2011).

In summary, the molecular cloning and characterization of the genomic DNA and full-length cDNA of the cytokines IL-1 $\beta$ and IL-8 from $P$. mesopotamicus are provided in the present study showing that these cytokines have structural similarities with other teleost species, but also present some features that appear to be specific for fish from the Characiformes order. Furthermore, transcript analysis indicates that these interleukins are constitutively expressed in all organs analyzed, with the highest levels found in the 
spleen for IL-1 $\beta$ and in the liver, gill and spleen for IL-8. Under pathogenic conditions, these genes are involved in the early response against bacterial infections, mainly in the spleen and head kidney.

To the best of our knowledge, this is the first comprehensive study investigating the biological properties of these two important cytokines in a fish from the Characiformes order, further contributing to a better understanding of the mechanisms coordinating the initial response against bacterial pathogens in teleosts.

\section{Acknowledgments}

The authors would like to thank Dr. Ricardo L. M. Sousa for the assistance with the handling of bacterial cultures and Dr. Nycolas L. Pereira for helping with fish sampling. This work was supported by the São Paulo Research Foundation - FAPESP (Grants 2017/18562-6 and 2017/26996-6) and the National Council for Scientific and Technological Development $-\mathrm{CNPq}$ (Grant 408281/2018-9).

\section{Conflict of Interest}

The authors declare that they have no competing interests.

\section{Authors Contributions}

MMC, FHS and AAMM conceived and designed the study; MMC collected the samples; MMC, CMM and IMQG performed gene expression analysis; MMC, ARC, FPL, ALA and ESV analyzed sequence data; MMC wrote the manuscript; FHS and AAMM revised final version of the manuscript; all authors read and approved the final version.

\section{References}

Allen SJ, Crown SE and Handel TM (2007) Chemokine: receptor structure, interactions, and antagonism. Annu Rev Immunol 25:787-820.

Arnold K, Bordoli L, Kopp J and Schwede T (2006) The SWISSMODEL workspace: a web-based environment for protein structure homology modelling. Bioinformatics 22:195-201.

Baggiolini M, Loetscher P and Moser B (1995) Interleukin-8 and the chemokine family. Int J Immunopharmacol 17:103-8.

Berkamp S, Park SH, De Angelis AA, Marassi FM and Opella JS (2017) Structure of monomeric Interleukin-8 and its interactions with the N-terminal Binding Site-I of CXCR1 by solution NMR spectroscopy. J Biomol NMR 69:111-121.

Carriero MM, Maia AAM, Sousa RLM and Henrique-Silva F (2016) Characterization of a new strain of Aeromonas dhakensis isolated from diseased pacu fish (Piaractus mesopotamicus) in Brazil. J Fish Dis 39:1285-1295.

Carriero MM, Henrique-Silva F, Caetano AR, Lobo FP, Alves AL, Varela ES, Del Collado M, Moreira GSA and Maia AAM (2018) Characterization and gene expression analysis of pacu (Piaractus mesopotamicus) inducible nitric oxide synthase (iNOS) following Aeromonas dhakensis infection. Fish Shellfish Immunol 74:94-100.
Chen L, He C, Baoprasertkul P, Xu P, Li P, Serapion J, Waldbieser G, Wolters W and Liu Z (2005) Analysis of a catfish gene resembling interleukin-8: cDNA cloning, gene structure, and expression after infection with Edwardsiella ictaluri. Dev Comp Immunol 29:135-42.

Cheng CS, Chen WT, Lee LH, Chen YW, Chang SY, Lyu PC and Yin HS (2011) Structural and functional comparison of cytokine interleukin-1 beta from chicken and human. Mol Immunol 48:947-55.

Chu CQ, Lu XJ, Li CH and Chen J (2014) Molecular characterization of a CXCL8-like protein from ayu and its effect on chemotaxis of neutrophils and monocytes/macrophages. Gene 548:48-55.

Claudiano GS, Yunis-Aguinaga J, Marinho-Neto FA, Miranda RL, Martins IM, Otani FS, Mundim AV, Marzocchi-Machado CM, Moraes JRE and Moraes FR (2019) Hematological and immune changes in Piaractus mesopotamicus in the sepsis induced by Aeromonas hydrophila.Fish Shellfish Immunol 88:259-265.

Clore GM, Appella E, Yamada M, Matsushima K and Gronenborn AM (1990) Three-dimensional structure of interleukin 8 in solution. Biochemistry 29:1689-96.

Corripio-Miyar Y, Bird S, Tsamopoulos K and Secombes CJ (2007) Cloning and expression analysis of two pro-inflammatory cytokines, IL-1 $\beta$ and IL-8, in haddock (Melanogrammus aeglefinus). Mol Immunol 44:1361-1373.

de Paula TG, de Almeida FL, Carani FR, Vechetti-Junior IJ, Padovani CR, Salomão RA, Mareco EA, Dos Santos VB and Dal-Pai-Silva M (2014) Rearing temperature induces changes in muscle growth and gene expression in juvenile pacu (Piaractus mesopotamicus). Comp Biochem Physiol B Biochem Mol Biol 169:31-7.

Dinarello CA (1997) Interleukin-1. Cytokine Growth Factor Rev 8:253-65.

Dinarello CA (2010) IL-1: Discoveries, controversies and future directions. Eur J Immunol 40:599-606.

Engelsma MY, Stet RJ, Saeij JP and Kemenade BMLV (2003) Differential expression and haplotypic variation of two interleukin-1 $\beta$ genes in the common carp (Cyprinus carpio L.). Cytokine 22:21-32.

Farias THV, Silva KR, Mariguela VC, Montassier HJ and Pilarski F (2018) Development of an indirect ELISA assay to evaluation of the adaptive immune response of pacu (Piaractus mesopotamicus). An Acad Bras Ciênc 90:3327-3335.

Ferre F and Clote P (2006) DiANNA 1.1: An extension of the DiANNA web server for ternary cysteine classification. Nucleic Acids Res 34:182-5.

Fujiki K, Gauley J, Bols NC and Dixon B (2003) Genomic cloning of novel isotypes of the rainbow trout interleukin-8. Immunogenetics 55:126-31.

Goodman RB, Forstrom JW, Osborn SG, Chi EY and Martin TR (1991) Identification of two neutrophil chemotactic peptides produced by porcine alveolar macrophages. J Biol Chem 266:8455-63.

Harun NO, Zou J, Zhang YA, Nie P and Secombes CJ (2008) The biological effects of rainbow trout (Oncorhynchus mykiss) recombinant interleukin-8. Dev Comp Immunol 32:673-681.

Herath HM, Elvitigala DA, Godahewa GI, Umasuthan N, Whang I, Noh JK and Lee J (2016) Molecular characterization and comparative expression analysis of two teleostean pro-inflammatory cytokines, IL-1beta and IL-8, from Sebastes schlegeli. Gene 575:732-42. 
Hong S, Zou J, Collet B, Bols NC and Secombes CJ (2004) Analysis and characterisation of IL-1 $\beta$ processing in rainbow trout, Oncorhynchus mykiss. Fish Shellfish Immunol 16:453-9.

Jimenez N, Coll J, Salguero FJ and Tafalla C (2006) Co-injection of interleukin 8 with the glycoprotein gene from viral haemorrhagic septicemia virus (VHSV) modulates the cytokine response in rainbow trout (Oncorhynchus mykiss). Vaccine 24:5615-26.

Kapustin Y, Souvorov A, Tatusova T and Lipman D (2008) Splign: algorithms for computing spliced alignments with identification of paralogs. Biol Direct 3:20.

Kendrick AA, Holliday MJ, Isern NG, Zhang F, Camilloni C, Huynh C, Vendruscolo M, Armstrong G and Eisenmesser EZ (2014) The dynamics of interleukin- 8 and its interaction with human CXC receptor I peptide. Protein Sci 23:464-80.

Kumar S, Stecher G and Tamura K (2016) MEGA7: Molecular Evolutionary Genetics Analysis Version 7.0 for bigger datasets. Mol Biol Evol 33:1870-4.

Lee DS, Hong SH, Lee HJ, Jun LJ, Chung JK, Kim KH and Jeong HD (2006) Molecular cDNA cloning and analysis of the organization and expression of the IL- $1 \beta$ gene in the Nile tilapia, Oreochromis niloticus. Comp Biochem Physiol A Mol Integr Physiol 143:307-14.

Lee EY, Park HH, Kim YT and Choi TJ (2001) Cloning and sequence analysis of the interleukin- 8 gene from flounder (Paralichthys olivaceous). Gene 274:237-43.

Li C and Yao CL (2013) Molecular and expression characterizations of interleukin-8 gene in large yellow croaker (Larimichthys crocea). Fish Shellfish Immunol 34:799-809.

Lin YP, Gao ZX and Zhan AB (2015) Introduction and use of non-native species for aquaculture in China: Status, risks and management solutions. Rev Aquacult 7:28-58.

Marinho-Neto FA, Claudiano GS, Yunis-Aguinaga J, Cueva-Quiroz VA, Kobashigawa KK, Cruz NRN, Moraes FR and Moraes JRE (2019) Morphological, microbiological and ultrastructural aspects of sepsis by Aeromonas hydrophila in Piaractus mesopotamicus.PLoS One 14:e0222626.

Morrison RN, Young ND and Nowak BF (2012) Description of an Atlantic salmon (Salmo salar L.) type II interleukin-1 receptor cDNA and analysis of interleukin-1 receptor expression in amoebic gill disease-affected fish. Fish Shellfish Immunol 32:1185-90.

MPA (2013) Boletim Estatístico da Pesca e Aquicultura 2011. Ministério da Pesca e Aquicultura, Brasília.

Mukaida N, Harada A and Matsushima K (1998) Interleukin-8 (IL-8) and monocyte chemotactic and activating factor (MCAF/MCP-1), chemokines essentially involved in inflammatory and immune reactions. Cytokine Growth Factor Rev 9:9-23.

Nakamura H, Yoshimura K, Jaffe HA and Crystal RG (1991) Interleukin-8 gene expression in human bronchial epithelial cells. J Biol Chem 266:19611-7.

Nicola N (1994) Guidebook to cytokines and their receptors. Oxford University Press, New York.

Oehlers SH, Flores MV, Hall CJ, O'Toole R, Swift S, Crosier KE and Crosier PS (2010) Expression of zebrafish cxcl8 (interleukin-8) and its receptors during development and in response to immune stimulation. Dev Comp Immunol 34:352-9.

Peddie S, McLauchlan PE, Ellis AE and Secombes CJ (2003) Effect of intraperitoneally administered IL-1 beta-derived peptides on resistance to viral haemorrhagic septicaemia in rainbow trout Oncorhynchus mykiss. Dis Aquat Organ 56:195-200.
Pelegrin P, Garcia-Castillo J, Mulero V and Meseguer J (2001) Interleukin-1 $\beta$ isolated from a marine fish reveals up-regulated expression in macrophages following activation with lipopolysaccharide and lymphokines. Cytokine 16:67-72.

Pelegrin P, Chaves-Pozo E, Mulero V and Meseguer J (2004) Production and mechanism of secretion of interleukin- $1 \beta$ from the marine fish gilthead seabream. Dev Comp Immunol 28:229-237.

Pettersen EF, Goddard TD, Huang CC, Couch GS, Greenblatt DM, Meng EC and Ferrin TE (2004) UCSF chimera - A visualization system for exploratory research and analysis. J Comput Chem 25:1605-1612.

Pleic IL, Secombes CJ, Bird S and Mladineo I (2014) Characterization of three pro-inflammatory cytokines, TNFalpha1, TNFalpha2 and IL-1beta, in cage-reared Atlantic bluefin tuna Thunnus thynnus. Fish Shellfish Immunol 36:98-112.

Qiu L, Zhang H, Yang K and Jiang S (2009) Molecular cloning and mRNA expression analysis of interleukin- 8 gene in Japanese sea perch (Lateolabrax japonicus). Mol Biol Rep 36:1099-105.

Reis MIR, do Vale A, Pereira PJB, Azevedo JE and dos Santos NMS (2012) Caspase-1 and IL-1 $\beta$ processing in a teleost fish. PLoS One 7:e50450.

Rosenkilde MM and Schwartz TW (2004) The chemokine system a major regulator of angiogenesis in health and disease. APMIS 112:481-95.

Sabat R, Grutz G, Warszawska K, Kirsch S, Witte E, Wolk K and Geginat J (2010) Biology of interleukin-10. Cytokine Growth Factor Rev 21:331-44.

Sanchez E, Coll J and Tafalla C (2007) Expression of inducible CC chemokines in rainbow trout (Oncorhynchus mykiss) in response to a viral haemorrhagic septicemia virus (VHSV) DNA vaccine and interleukin 8. Dev Comp Immunol 31:916-926.

Scapigliati G, Buonocore F, Bird S, Zou J, Pelegrin P, Falasca C, Prugnoli D and Secombes CJ (2001) Phylogeny of cytokines: molecular cloning and expression analysis of sea bass Dicentrarchus labrax interleukin-1 $\beta$. Fish Shellfish Immunol 11:711-26.

Schmittgen TD and Livak KJ (2008) Analyzing real-time PCR data by the comparative $\mathrm{Ct}$ method. Nat Protoc 3:1101-1108.

Secombes CJ, Bird S, Cunningham C and Zou J (1999) Interleukin-1 in fish. Fish Shellfish Immunol 9:335-343.

Secombes CJ, Wang T and Bird S (2011) The interleukins of fish. Dev Comp Immunol 35:1336-45.

Seppola M, Larsen AN, Steiro K, Robertsen B and Jensen I (2008) Characterisation and expression analysis of the interleukin genes, IL-1 $\beta$, IL-8 and IL-10, in Atlantic cod (Gadus morhua L.). Mol Immunol 45:887-897.

Stothard P (2000) The sequence manipulation suite: JavaScript programs for analyzing and formatting protein and DNA sequences. Biotechniques 28:1102-1104.

Strieter RM, Polverini PJ, Kunkel SL, Arenberg DA, Burdick MD, Kasper J, Dzuiba J, Van Damme J, Walz A, Marriott D et al. (1995) The functional role of the ELR motif in CXC chemokine-mediated angiogenesis. J Biol Chem 270:27348-57.

Sun JS, Zhao L and Sun L (2011) Interleukin-8 of Cynoglossus semilaevis is a chemoattractant with immunoregulatory property. Fish Shellfish Immunol 30:1362-1367.

Thompson JD, Higgins DG and Gibson TJ (1994) Clustal-W: Improving the sensitivity of progressive multiple sequence alignment through sequence weighting, position-specific gap penalties and weight matrix choice. Nucleic Acids Res 22:4673-4680.

van der Aa LM, Chadzinska M, Golbach LA, Ribeiro CM and Kemenade BMLV (2012) Pro-inflammatory functions of 
carp CXCL8-like and $\mathrm{CXCb}$ chemokines. Dev Comp Immunol 36:741-50.

Wang E, Liu T, Wu J, Wang K, Chen D, Geng Y, Huang X, Ouyang P, Lai W and Ai X (2019) Molecular characterization, phylogenetic analysis and adjuvant effect of channel catfish interleukin-1 $\beta$ s against Streptococcus iniae. Fish Shellfish Immunol 87:155-165.

Wang EL, Wang J, Long B, Wang KY, He Y, Yang Q, Chen DF, Geng Y, Huang XL, Ouyang P et al. (2016) Molecular cloning, expression and the adjuvant effects of interleukin- 8 of channel catfish (Ictalurus Punctatus) against Streptococcus iniae. Sci Rep 6:29310.

Wang GL, Wang MC, Zhang XW, Chang MX, Xie HX and Nie P (2017) Molecular cloning, biological effect, and tissue distribution of interleukin-8 protein in mandarin fish (Siniperca chuasti) upon Flavobacterium columnare infection. Fish Shellfish Immunol 66:112-119.

Wang TT, Song XH, Bao GM, Zhao LX, Yu X and Zhao J (2013) Molecular characterization, expression analysis, and biological effects of interleukin-8 in grass carp Ctenopharyngodon idellus. Fish Shellfish Immunol 35:1421-32.
Wang Y, Wang Q, Baoprasertkul P, Peatman E and Liu Z (2006) Genomic organization, gene duplication, and expression analysis of interleukin-1 $\beta$ in channel catfish (Ictalurus punctatus). Mol Immunol 43:1653-64.

Witmer GW and Fuller PL (2011) Vertebrate species introductions in the United States and its territories. Curr Zool 57:559-567.

Yanez MA, Catalan V, Apraiz D, Figueras MJ and MartinezMurcia AJ (2003) Phylogenetic analysis of members of the genus Aeromonas based on gyrB gene sequences. Int J Syst Evol Microbiol 53:875-83.

Zhang X, Liu P, Zhang C, Chiewchengchol D, Zhao F, Yu HB, Li JY, Kambara H, Luo KY, Venkataraman A et al. (2017) Positive Regulation of Interleukin-1 $\beta$ Bioactivity by Physiological ROS-Mediated Cysteine S-Glutathionylation. Cell Rep 20:224-235

Zou J, Grabowski PS, Cunningham C and Secombes CJ (1999) Molecular cloning of interleukin $1 \beta$ from rainbow trout Oncorhynchus mykiss reveals no evidence of an ice cut site. Cytokine 11:552-560.

Associate Editor: Vera Maria Fonseca de Almeida e Val

License information: This is an open-access article distributed under the terms of the Creative Commons Attribution License (type CC-BY), which permits unrestricted use, distribution and reproduction in any medium, provided the original article is properly cited. 